\title{
Does the Glass Ceiling Exist?: A Cross-National Perspective on Gender Income Mobility
}

\author{
Ira N. Gang \\ Rutgers University \\ gang@economics.rutgers.edu \\ John Landon-Lane \\ Rutgers University \\ lane@economics.rutgers.edu \\ Myeong-Su Yun* \\ Tulane University \\ msyun@tulane.edu
}

March 24, 2003

\footnotetext{
${ }^{*}$ Corresponding Author: John Landon-Lane, Economics Department, NJH, Rutgers University, 75 Hamilton St, New Brunswick NJ 08901-1248, phone: (732) 932-7691, fax: (732) 932-7416. An earlier incarnation of this paper was presented at the 5th International German Socio-Economic Panel User Conference, July 3-4, 2002, Berlin, Germany.
} 


\title{
Does the Glass Ceiling Exist?: A Cross-National Perspective on Gender Income Mobility
}

\begin{abstract}
We compare male and female upward labor income mobility in Germany and the United States using the GSOEP-PSID Cross-National Equivalent File. Our main interest is to test whether a glass ceiling exists for women. Conventional thinking about the glass ceiling highlights the belief that the playing field is level for women and men in the labor market up to a certain point, after which there is an effective limit on advancement for women. We examine the glass ceiling hypothesis by looking at the income dynamics the movement of women and men through the distribution of income over time. We find that there is considerable evidence in favor of a glass ceiling both in Germany and the United States with men having approximately a 30\% premium in their upward income mobility compared to women in the upper income classes. We also find significant, but smaller, differences at middle and low income levels for both countries.
\end{abstract}

Keywords: glass ceiling, mobility, Markov chain, income distribution dynamics, gender discrimination

JEL Classification: D3, D63, J7 


\section{Introduction}

In 1995 the U.S. Department of Labor's Glass Ceiling Commission issued a report saying: "a glass ceiling exists and that it operates substantially to exclude minorities and women from top levels of management." [Good for Business: Making Full Sense of the Nation's Human Capital (1995, page 7)]. The glass ceiling concept is popular in the press, in government circles and in general conversation. The economics literature has hardly touched the topic, though the few articles that have dealt with the issue have found glass ceilings [Duleep and Sanders (1992), McDowell, L. D. Singell and Ziliak (1999), Athey, Avery and Zemksy (2000), and Albrecht, Björklund and Vroman (2003)]. ${ }^{1}$

The glass ceiling is generally thought of as the transparent but real barriers which impede qualified women and other minorities from advancing up the job ladder into high level management positions. In the economics literature, the glass ceiling has been variously (and relatedly) defined to be: 1) discrimination at the top [Duleep and Sanders (1992)]; 2) accelerated widening of the gender wage gap in the upper tail of the wage distribution [Albrecht et al. (2003)]; 3) disparity in promotion opportunities by gender for those with strong labor market attachment [McDowell et al. (1999)]; and 4) homogenous gender distribution at the upper levels of firms with diverse gender distribution at the lower levels [Athey et al. (2000)].2

Our interpretation is that the glass ceiling hypothesis captures the idea that women and other minorities are less likely to be promoted - they have lower upward mobility, especially at the higher income levels - than their male majority colleagues. Effectively

\footnotetext{
${ }^{1} \mathrm{~A}$ March 24, 2003 search on Econlit (http://www.econlit.org), an index of professional economics journals, found only 14 references with the term "glass ceiling" in the abstract or title. Only three of these were in what would generally be called mainstream economics journals. A similar search of the SSRN database (http://www.ssrn.com), a repository of discussion papers in economics, came up with 7 references.

${ }^{2}$ In related work, Booth, Francesconi and Frank (2003) argue that it is not differences in the promotion rate but the differential rates of increases of salary/wages associated with the promotion that may explain why women's income is lower than men's.
} 
it means that mobility is constrained. The existence of a glass ceiling implies that the upper level of the employment distribution - and by implication the upper end of the labor income distribution - remains less diverse than the entry level in gender composition. In terms of labor income mobility we expect to see here relatively similar patterns of upward mobility for women and men within the lower and middle parts of the distribution, but little upward movement of women relative to men across the upper tail of the distribution. ${ }^{3}$

We examine the labor income mobility of men and women in Germany and the United States using the GSOEP-PSID Cross-National Equivalent File. Our main interest is to test whether a glass ceiling exists for women relative to men. A thorough examination of the glass ceiling hypothesis requires a detailed data set that would contain information at the micro level on promotions and salaries (see Ransom and Oaxaca (2003) for use of intrafirm information). The data that we use does not include all the information needed to study promotions and salary increases at the firm level. However, the existence of a glass ceiling for women, for example, would imply that there would be observed differences in the pattern of income mobility between men and women. We examine the glass ceiling hypothesis by looking at the dynamics of the income distribution - the upward movement of women and men through the distribution of income over time. Evidence of significant differences in upward income mobility for women would be consistent with the glass ceiling hypothesis while evidence of equal upward mobility between men and women would be evidence against the glass ceiling hypothesis.

We study the income mobility of men and women by modelling the dynamics of the income distribution as a first order Markov chain. Bayesian methods are used to characterize the distribution of all the functions of the transition probability matrix. In

\footnotetext{
${ }^{3}$ While obviously related, the existence of a glass ceiling does not necessarily imply that there is discrimination. McDowell et al. (1999) find evidence of a glass ceiling in the academic economics profession. However, they also find that the publishing profile for female economists is lower throughout their careers relative to men.
} 
particular, we are able to estimate the probabilities of an individual moving from one income classification to another, formally compare and contrast various mobility indices across different subsamples of the data, and formally compare and test various hypotheses on the convergence properties of the income distribution. We are most interested in measuring upward income mobility and testing different hypotheses on the transitional dynamics of the income distribution.

In the next section we lay out the basic elements needed in modelling income distribution dynamics. In Section 3 we discusses various income mobility measures and characterize the upward mobility measures we use to examine whether or not there is a glass ceiling. Section 4 discuss our data and priors. Results are discussed in section 5 . Section 6 concludes.

\section{Modelling Income Distribution Dynamics}

The dynamics of labor income is studied in this paper using a first order Markov chain. The use of Markov chain models to study income dynamics has a long history with notable contributions by Champernowne (1953), Shorrocks (1976) and more recently by Buchinsky and Hunt (1999).

One of the most appealing aspects of using a Markov chain to model income dynamics across individuals is the ability to investigate issues such as differences in income mobility over time, among subgroups of the population. The Markov assumption is a natural way of thinking about income dynamics while imposing only minimal theoretical structure. Gang, Landon-Lane and Yun (2003) formally develop measures of upward and downward mobility and show how these can be aggregated into standard Markov chain mobility measures. In studying the income dynamics, we study the movement across income classifications from one period to the next, and ultimately to the limiting period. To do 
this we need to specify the initial income distribution, estimate the transition probabilities and characterize the limiting income distribution. Here we offer a discussion of the modelling and estimation strategy.

Let there be a finite number, $C$, of income classifications and let $\pi_{t}$ represent the income distribution over these $C$ income classes at time $t$. The variable $\pi_{t}$ defines the "state" of the world at time $t$. The first order Markov assumption implies that the state of the world today is only dependent on $\pi_{t-1}$. That is,

$$
P\left(\pi_{t} \mid \pi_{t-1}, \pi_{t-2}, \ldots, \pi_{t-j}\right)=P\left(\pi_{t} \mid \pi_{t-1}\right) \quad \forall j=2,3, \ldots,
$$

where $P($.$) represents the conditional probability distribution of \pi$. Define the probability of transition from class $i$ in period $t$ - 1 to class $j$ in period $t$ to be $p\left(\pi_{t}=j \mid \pi_{t-1}=i\right) \equiv p_{i j}$ so that the Markov transition matrix, $\mathbf{P}$, can be defined as $\mathbf{P}=\left[p_{i j}\right]$. Then the first order Markov chain model is

$$
\pi_{t}^{\prime}=\pi_{t-1}^{\prime} \mathbf{P}
$$

It is simple to show that $\pi_{t}^{\prime}=\pi_{0}^{\prime} \mathbf{P}^{t}$, where $\pi_{0}$ is the initial income distribution. The invariant or limiting income distribution, $\bar{\pi}$, is any distribution that satisfies

$$
\bar{\pi}^{\prime}=\bar{\pi}^{\prime} \mathbf{P}
$$

The invariant distribution is unique if there is only one eigenvalue of $\mathbf{P}$ with modulus one. $^{4}$

This paper uses Bayesian methods to estimate and make inferences from the Markov chain model outlined above. One important benefit of using Bayesian methods is that

\footnotetext{
${ }^{4}$ Implicitly we are assuming that the eigenvalues have been ordered from highest to lowest in terms of magnitude. As $\mathbf{P}$ is row stochastic we know that the highest eigenvalue, in terms of magnitude, is 1. If the magnitude of the second eigenvalue is strictly less than 1 then we know that the invariant distribution is unique.
} 
it is simple to characterize the distribution of any function of the primal parameters, $\pi_{0}$ and $\mathbf{P}$, of the model. For example, we are able to characterize the distribution of the invariant distribution, $\bar{\pi}$; a highly non-linear function of $\mathbf{P}$. Other functions of $\mathbf{P}$ that are of interest include various mobility indices such as the probability of moving to a higher income class.

Before discussing in detail the particular measures of mobility and the tests used in this paper, we discuss our sampling scheme. We observe $N$ individuals over $T$ time periods and place them into $C$ classifications. Let $i \in\{1,2, \ldots, C\}, n \in\{1,2, \ldots, N\}$, and let $t \in\{1,2, \ldots, T\}$. For each individual, $n$, define

$$
\delta_{n i t}=\left\{\begin{array}{ll}
1 & \text { if individual } n \text { is in class } i \text { for time period } t \\
0 & \text { else }
\end{array} .\right.
$$

For each individual, $n$, and for each time period $t$ we observe the individuals' income class $s_{n t} \in\{1,2,3, \ldots, C\} \cup\{0\} .{ }^{5}$ Let $S_{N T}=\left\{\left\{s_{n t}\right\}_{n=1}^{N}\right\}_{t=1}^{T}$ be the information set at time $T$. Define $k_{i 0}=\sum_{n=1}^{N} \delta_{n i 0}$ as the number of individuals who are in class $i$ in the initial period and define $k_{i j}=\sum_{n=1}^{N} \sum_{t=1}^{T} \delta_{n i(t-1)} \delta_{n j t}$ as the total number of transitions from class $i$ in time period $t-1$ to class $j$ in time period $t$ across all time periods. The matrix $\mathbf{K}=\left[k_{i j}\right]$ is the observed sample transition matrix. ${ }^{6}$

Let $\theta=\left(\pi_{0}, \mathbf{P}\right)^{\prime}$. The data density, or likelihood function, for the model defined in (2) is

$$
p\left(S_{N T} \mid \theta\right) \propto \prod_{i=1}^{C} \pi_{i 0}^{k_{i 0}} \prod_{j=1}^{C} p_{i j}^{k_{i j}}
$$

which is the kernel of the product of two independent multivariate Dirichlet (Beta) dis-

\footnotetext{
${ }^{5}$ This notation allows for the possibility of an unbalanced sample in that $s_{n t}=0$ implies that individual $n$ is missing from the sample in period t.

${ }^{6}$ The observed initial distribution, $k_{0}$ and the observed data transition matrix, $\mathbf{K}$, are both functions of the information set, $S_{N T}$. Hence $S_{N T}$ and $\left(k_{0}, \mathbf{K}\right)$ are interchangeable in the definitions of the data density. For brevity we use $S_{N T}$.
} 
tributions. Natural conjugate priors for $\pi_{0}$ and $\mathbf{P}$ are also independent Dirichlet distributions defined as

$$
p\left(\pi_{0}\right)=\left[\frac{\Gamma\left(\sum_{i=1}^{C} a_{i 0}\right)}{\prod_{i=1}^{C} \Gamma\left(a_{i 0}\right)}\right] \prod_{i=1}^{C} \pi_{i 0}^{\left(a_{i 0}-1\right)}
$$

and

$$
p(\mathbf{P})=\prod_{i=1}^{C}\left[\frac{\Gamma\left(\sum_{j=1}^{C} a_{i j}\right)}{\prod_{j=1}^{C} \Gamma\left(a_{i j}\right)}\right] \prod_{j=1}^{C} p_{i j}^{\left(a_{i j}-1\right)},
$$

where $\Gamma($.$) is the Gamma function. The prior density is then defined as p(\theta)=p\left(\pi_{0}\right) p(\mathbf{P})$.

Here the priors are parameterized by the vector $a_{0}=\left(a_{10}, \ldots, a_{C 0}\right)^{\prime}$ and $\mathbf{A}=\left[a_{i j}\right]$. The priors have a notional sample interpretation. We can think of $a_{i 0}-1$ as the number of individuals in the $i^{\text {th }}$ class of the initial income distribution of a notional sample and $a_{i j}-1$ can be interpreted as the total number of transitions from class $i$ in period $t-1$ to class $j$ in period $t$ for the notional sample. Assuming that the priors are independent then the posterior distribution for (2) is

$$
p\left(\theta \mid S_{N T}\right) \propto\left[\frac{\Gamma\left(\sum_{i=1}^{C} a_{i 0}\right)}{\prod_{i=1}^{C} \Gamma\left(a_{i 0}\right)}\right] \prod_{i=1}^{C} \pi_{i 0}^{\left(k_{i 0}+a_{i 0}-1\right)} \prod_{i=1}^{C}\left\{\left[\frac{\Gamma\left(\sum_{j=1}^{C} a_{i j}\right)}{\prod_{j=1}^{C} \Gamma\left(a_{i j}\right)}\right] \prod_{j=1}^{C} p_{i j}^{\left(k_{i j}+a_{i j}-1\right)}\right\} .
$$

The joint posterior density kernel in (8) is the kernel for the product of two Dirichlet distributions. The posterior distribution for $\pi_{0}$, the initial income distribution, is Dirichlet with parameters $\left(k_{10}+a_{10}, \ldots, k_{C 0}+a_{C 0}\right)^{\prime}$. The posterior distribution for $\mathbf{P}$ is the product of $C$ independent Dirichlet distributions with parameters $\left(k_{i 1}+a_{i 1}, \ldots, k_{i C}+a_{i C}\right)^{\prime}$ for $i=1, \ldots, C$.

We are interested in calculating conditional expectations, $E\left(g(\theta) \mid S_{N T}\right)$, for any well defined function, $g(\theta)$, of the parameters of the Markov chain. Examples include the invariant income distribution and measures of upward mobility, which we define in Section 3. It is a simple matter to make identical and independent draws from these independent Dirichlet distributions using the method described in Devroye (1986). 
Let $\Theta^{L}=\left\{\theta^{(l)}\right\}_{l=1}^{L}$ be the i.i.d. samples from the posterior distribution, $p\left(\theta \mid S_{N T}\right)$. By the law of large numbers the conditional expectation, $E\left(g(\theta) \mid S_{N T}\right)$, can be approximated by the simple arithmetic average,

$$
\bar{g}_{L}=L^{-1} \sum_{l=1}^{L} g\left(\theta^{(l)}\right)
$$

This simple result allows us to characterize all functions, $g(\theta)$, of the primal parameters for which $g(\theta)$ is well defined. Particular functions of interest to us are defined in the next section.

\section{Mobility and the Glass Ceiling}

Testing for evidence of a glass ceiling involves measuring the mobility of men and women. There are many measures of overall income mobility that can be defined (Shorrocks (1978) and Geweke, Marshall and Zarkin (1986)). A measure of overall income mobility that is commonly reported in the literature is the measure due to Shorrocks (1978),

$$
\mathcal{M}_{s}(\mathbf{P})=\frac{C-\operatorname{tr}(\mathbf{P})}{C-1}
$$

which is the inverse of the harmonic mean of the expected length of stay in an income class, scaled by a factor of $C /(C-1)$. This index satisfies the monotonicity, immobility and strong immobility persistence criteria and hence is internally consistent. ${ }^{7}$

Gang et al. (2003) show how this measure can be decomposed into its upward and downward income mobility components. We also show that these upward and downward income mobility indices are internally consistent with respect to the persistence criteria noted above. The measure of upward mobility that we use in this paper is

\footnotetext{
${ }^{7}$ See Geweke et al. (1986) for a complete discussion on the properties of these mobility indices.
} 


$$
\mathcal{M}_{U}(\mathbf{P})=\frac{1}{C-1} \sum_{c=1}^{C-1} \mathcal{M}_{U \mid c}(\mathbf{P})
$$

where

$$
\mathcal{M}_{U \mid c}(\mathbf{P})=\sum_{j=c+1}^{C} p_{c j}
$$

Here, $\mathcal{M}_{U \mid c}$ measures the probability of moving up from income class $c$ to any income class above $c$, and $\mathcal{M}_{U}$ is the average probability of moving to a higher income class. These measures allow us to characterize any differences between men and women in terms of ability of moving to a higher income class.

In order to determine whether there is any evidence in support of the glass ceiling hypothesis we test whether men have more upward mobility than women. The general format of the test is as follows. Let $\mathcal{S}$ be any particular statistic (for example $\mathcal{M}_{U}$ ) that we are interested in. Let

$$
d_{l}= \begin{cases}1 & \text { if } \mathcal{S}^{M}>\mathcal{S}^{F} \\ 0 & \text { else }\end{cases}
$$

Let $\psi=\left(\theta_{M}, \theta_{F}\right)^{\prime}$ where $\theta_{M}$ and $\theta_{F}$ are the underlying parameters of the first order Markov chain for men and women respectively. Our function of interest, $g(\psi)$, is the posterior probability that the statistic, $\mathcal{S}$, is bigger for men than for women, and is given by

$$
\begin{aligned}
g(\psi) & =p\left(\mathcal{S}^{M}>\mathcal{S}^{F}\right) \\
& =\int_{\tilde{\Psi}} p_{\psi}\left(\psi \mid S_{N T}\right) d p\left(\psi \mid S_{N T}\right)
\end{aligned}
$$

where $\tilde{\Psi}$ is the region of the support of the posterior in which $\mathcal{S}^{M}>\mathcal{S}^{F}$ and $p_{\psi}\left(\psi \mid S_{N T}\right)$ 
is the joint posterior density of the random variable $\psi^{8}$

An estimator of $p\left(\mathcal{S}_{M}>\mathcal{S}_{F}\right)$ is

$$
p\left(\mathcal{S}_{M}>\mathcal{S}_{F}\right)=L^{-1} \sum_{l=1}^{L} d_{l}
$$

for some sample $\left\{d_{l}\right\}_{l=1}^{L}$. In practice we have i.i.d. draws $\left\{\theta_{x}^{(l)}\right\}_{l=1}^{L}$ from the posterior distribution $p\left(\theta_{x} \mid S_{N T}\right)$ for $x \in\{M, F\}$. Then if $\mathcal{S}=\mathcal{M}_{U}$, for example, we can compute the posterior probability that men have a higher upward income mobility then women.

A value of $p\left(\mathcal{S}_{M}>\mathcal{S}_{F}\right)=1$ can be interpreted as the distribution of $\mathcal{S}_{M}$ being completely to the right of the distribution of $\mathcal{S}_{F}$. Conversely, a value of 0 implies that the distribution of $\mathcal{S}_{M}$ is completely to the left of distribution of $\mathcal{S}_{F}$. Therefore, the closer the value of $p\left(\mathcal{S}_{M}>\mathcal{S}_{F}\right)$ is to 1 the further to the right is the distribution of $\mathcal{S}_{M}$ relative to the distribution of $\mathcal{S}_{F}$.

\section{Data and Prior Distribution}

\subsection{Data}

In order to study gender differences in the upward mobility of labor income, we use samples drawn from two panel data sets, the Panel Study of Income Dynamics (PSID) from the USA and the German Socio-Economic Panel (GSOEP). The study is facilitated by using PSID and GSOEP files from the Cross-National Equivalent File (CNEF), which makes the information in PSID and GSOEP directly comparable. ${ }^{9}$ The PSID-CNEF and

\footnotetext{
${ }^{8}$ In practice we assume that the distribution for men and women are independent so that $p_{\psi}\left(\psi \mid S_{N T}\right)=$ $p\left(\theta^{M} \mid S_{N T}\right) p\left(\theta^{F} \mid S_{N T}\right)$.

${ }^{9}$ PSID-CNEF and GSOEP-CNEF are available thanks to efforts of researchers and staff in Cornell University and the German Institute for Economic Research (DIW). For details of making equivalent files across countries, see the homepage of this project, http://www.human.cornell.edu/pam/gsoep/equivfil.cfm.
} 
GSOEP-CNEF contain information regarding not only demographic characteristics but also labor market activities including labor income. Our variable of interest is real labor income, which we calculate using data from the CNEF. We deflate labor income using the consumer price index (base year: 1991) and convert German Marks to US dollars using a purchasing power parity exchange rate (PPP) in $1991 .{ }^{10}$ We convert Marks to dollars at purchasing power parity to facilitate comparison between the United States and Germany and to make our comparisons of upward mobility in the United States and in Germany more transparent. We assign the class of workers based on their "absolute" amount of labor income, not their "relative" position in the distribution of labor income.

We exclude the over-sample of low-income families from PSID and utilize the West German sample from the GSOEP (sample A). We also excluded those who work in agriculture. The decision of transition period involves a number of considerations; given the data we have some flexibility over what this length could have been. There are a total of thirteen years in the sample for which we have comparable PSID and GSOEP data, so we could have chosen a transition period as short as one year in length or as long as thirteen years in length. The transition period needs to be long enough to allow for an individual's income change. One year is generally too short, while thirteen years is a long enough period for most individuals to have changes in their real income. However, the longer the transition period the lower the chance that an individual is sampled for all intervening years. In Section 5 we report results for a finite state Markov chain with ten income classifications. The transition matrix, $\mathbf{P}$, therefore contains 100 parameters that must be estimated. If we choose a thirteen year transition we end up with only a small number of women in our sample (see Table 1), which would not allow us to estimate $\mathbf{P}$ with any accuracy. Therefore, we use a transition period of five years in an attempt to achieve a balance between the transition period being long enough to allow individuals

\footnotetext{
${ }^{10}$ The PPP in 1991 is $2.09 \mathrm{DM}$ per US dollar, while the exchange rate in the same year is $1.66 \mathrm{DM}$ per US dollar.
} 
to have a significant change in their income and the sample size being large enough to allow for $\pi_{0}$ and $\mathbf{P}$ to be estimated accurately.

We construct an unbalanced panel consisting of three transition sub-periods (1984-1988, 1988-1992 and 1992-1994) where an individual is included in a transition period if they report income from a full-time job for all years covered by that transition period. We focus on workers who have strong attachment to the labor market, because the issue of the glass ceiling is more relevant to workers with substantial labor market involvement. Therefore, we restrict the sample to people who hold full-time jobs continuously for five years during at least one of three transition sub-periods. This eliminates workers who leave the full-time labor force temporarily in the middle of an observed transition period. We call the full-time job holders for five years during one of three sub-periods as "career-oriented workers," or in short, "career workers."

Full-time workers are those who work 35 hours or more per week on average. We study only workers not younger than 25 years in the beginning year and not older than 60 years in the ending year of the period. That is, we select people from age 25 to 55 at the start of each five year transition.

Summary statistics for our (unbalanced) panel can be found in Table 1. Sample sizes and descriptive statistics for the whole panel of full-time career workers and for the separate transition periods are reported. In total, our panel for the United States comprises 1642 individuals with 1035 men and 607 women. Our panel for Germany comprises 2261 individuals with 1776 men and 485 women. In all transition periods (and in the whole sample) there are significantly less women than men. This is particularly true in Germany where the number of women present in the sample as a percentage of men range from $22 \%$ to $27 \%$. This is much lower than in the United States panel where the number of women in the sample as a percentage of men range from $48 \%$ to $57 \%$. This could be due, for example, to women having a lower labor market participation in Germany. However, 
the sample size for the German panel is much higher so the actual number of women in the panel panel is reasonably similar across countries.

Table 1: Summary Statistics for Panel United States

Germany

Men Women All Men Women All

\section{All Transitions}

Sample Size

1 transition $^{a}$

1035

607

1642

1776

485

2261

2 transitions $^{b} \quad 301$

372

908

769

294

1063

3 transitions $^{c} \quad 198$

173

474

571

130

701

260

436

61

497

$\begin{array}{lllllll}\text { Median }^{d} & \$ 26,344 & \$ 18,391 & \$ 23,000 & \$ 23,740 & \$ 18,364 & \$ 22,562 \\ \text { 1st Quartile } & \$ 17,907 & \$ 12,579 & \$ 15,352 & \$ 18,956 & \$ 13,848 & \$ 17,783 \\ \text { 3rd Quartile } & \$ 37,707 & \$ 26,222 & \$ 33,149 & \$ 31,361 & \$ 23,565 & \$ 29,843 \\ \text { IQR }^{e} & \$ 19,799 & \$ 13,643 & \$ 17,797 & \$ 12,405 & \$ 9,717 & \$ 12,060\end{array}$

1st Transition (1984-1988)

\begin{tabular}{lcccccc}
\hline Sample Size & 519 & 248 & 767 & 1139 & 251 & 1390 \\
Median & $\$ 24,920$ & $\$ 16,687$ & $\$ 20,997$ & $\$ 21,679$ & $\$ 16,530$ & $\$ 20,586$ \\
1st Quartile & $\$ 16,152$ & $\$ 11,288$ & $\$ 13,836$ & $\$ 17,242$ & $\$ 12,222$ & $\$ 16,094$ \\
3rd Quartile & $\$ 35,757$ & $\$ 23,591$ & $\$ 31,446$ & $\$ 28,381$ & $\$ 21,157$ & $\$ 26,708$ \\
IQR & $\$ 19,605$ & $\$ 12,304$ & $\$ 17,610$ & $\$ 11,140$ & $\$ 8,936$ & $\$ 10,604$
\end{tabular}

\begin{tabular}{lcccccc} 
2nd Transition & $(1988-1992)$ & & & & \\
\hline Sample Size & 633 & 322 & 955 & 1116 & 253 & 1369 \\
Median & $\$ 26,519$ & $\$ 18,966$ & $\$ 23,301$ & $\$ 24,205$ & $\$ 18,752$ & $\$ 22,964$ \\
1st Quartile & $\$ 18,391$ & $\$ 13,003$ & $\$ 15,806$ & $\$ 19,494$ & $\$ 14,527$ & $\$ 18,336$ \\
3rd Quartile & $\$ 37,864$ & $\$ 27,185$ & $\$ 33,333$ & $\$ 31,739$ & $\$ 23,778$ & $\$ 30,156$ \\
IQR & $\$ 19,473$ & $\$ 14,182$ & $\$ 17,527$ & $\$ 12,244$ & $\$ 9,252$ & $\$ 11,820$
\end{tabular}

$\begin{array}{lcccccc}\text { 3rd Transition } & (1992-1996) & & & & \\ \text { Sample Size } & 580 & 334 & 914 & 964 & 233 & 1197 \\ \text { Median } & \$ 27,658 & \$ 19,964 & \$ 24,505 & \$ 26,231 & \$ 20,338 & \$ 24,943 \\ \text { 1st Quartile } & \$ 19,417 & \$ 13,889 & \$ 16,782 & \$ 20,869 & \$ 15,764 & \$ 19,693 \\ \text { 3rd Quartile } & \$ 39,585 & \$ 28,596 & \$ 34,951 & \$ 34,141 & \$ 26,228 & \$ 32,378 \\ \text { IQR } & \$ 20,168 & \$ 14,708 & \$ 18,169 & \$ 13,272 & \$ 10,464 & \$ 12,685\end{array}$

${ }^{a}$ This refers to all individuals in the panel that are present in only one transition.

${ }^{b}$ This refers to all individuals in the panel that are present in only two transitions.

${ }^{c}$ This refers to all individuals in the panel that are present in all three transitions.

${ }^{d}$ All incomes are in 1991 US dollars.

${ }^{e}$ Interquartile range. 
With respect to median real incomes it is clear that in both the United States and in Germany, men have a higher median income than women. Over time there has been a increase in median income in both countries but the gap between men and women has remained almost constant. Men in the United States consistently have a higher median real income than their counterparts in Germany while women in the two countries have very similar median real incomes. Finally, the income distribution in Germany is less diffuse than in the United States, as evidenced by the German interquartile ranges being considerable smaller than their United States counterparts. Overtime, however there appears to be a slight widening of the interquartile ranges for both men and women in both countries. This increase is bigger in Germany.

Before reporting the results, however, we first discuss the prior distributions used in our analysis. The prior distributions are described in Section 4.2 and the results are reported in Section 5 below.

\subsection{Prior Distributions}

This paper uses Bayesian methods to estimate and make inferences from the Markov chain model outlined in Section 3. One important benefit of using Bayesian methods is that it is simple to characterize the distribution of any function of the primal parameters, $\pi_{0}$ and $\mathbf{P}$, of the model and any, possibly non-linear, function of these primal parameters. In this paper, the functions of the primal parameters that we are interested in are the various mobility measures and the limiting distribution described above.

In order to implement our estimation strategy we need to construct priors for the unknown parameters of our model. The unknown parameters of the first order Markov chain model are $\pi_{0}$ and $\mathbf{P}$. We propose conjugate Dirichlet priors for $\pi_{0}$ and $\mathbf{P}$ parameterized by the vector $a_{0}$ and the matrix $\mathbf{A}$ respectively. Noting that the prior has a notional data 
interpretation (see Section 2), we propose priors that are generated from a notional data set that is one tenth the size of the observed sample.

To be consistent across genders and countries, we devise one basis prior, then multiply a scale factor based on the sample size. The basis prior is constructed as follows: Suppose that the sample consists of one thousand individuals. The prior would be parameterized so that it could be interpreted as coming from a notional sample of 100 individuals. ${ }^{11}$

The prior distributions, $p(\theta)$, for all data sets used in this paper are scalar multiples of the following basis prior distribution. Table 2 contains the values for $a_{0}$, the parameter that defines the Dirichlet prior for $\pi_{0}$ where there are ten income classifications (see Section 5 for details of the income classifications used). The notional sample size, for the basis prior, is 100 with each individual having equal prior probability of being a member of any particular income class. The prior for the transition matrix, $\mathbf{P}$, is similarly defined. Table 3 contains the prior parameters, $\mathbf{A}$, that define the prior for $\mathbf{P}$.

Table 2: Initial Distribution Prior: $a_{0}$

\begin{tabular}{ccccccccccc} 
Income Class & 1 & 2 & 3 & 4 & 5 & 6 & 7 & 8 & 9 & 10 \\
\hline$a_{i 0}$ & 11 & 11 & 11 & 11 & 11 & 11 & 11 & 11 & 11 & 11
\end{tabular}

The prior for $\mathbf{P}$ has the characteristic, in order to be consistent with $a_{0}$, that there are ten individuals initially in each income class. We have designed the matrix $\mathbf{A}$ so that the highest prior probability is given to an individual staying in the same income class that she started in with decreasing probability given to moves further away from the starting income class.

\footnotetext{
${ }^{11}$ It should be noted, however, that there is a positive externality in including prior information in that if the prior is suitably defined, none of the parameters defining the Dirichlet distribution in the posterior will be zero. This allows for easy sampling from the posterior.
} 
Table 3: Transition Matrix Prior: A

\begin{tabular}{ccccccccccc} 
Income Class & 1 & 2 & 3 & 4 & 5 & 6 & 7 & 8 & 9 & 10 \\
\hline$A_{1 j}$ & 6.21 & 3.60 & 2.30 & 1.65 & 1.13 & 1.06 & 1.01 & 1.01 & 1.01 & 1.01 \\
$A_{2 j}$ & 3.06 & 5.13 & 3.06 & 2.03 & 1.51 & 1.10 & 1.05 & 1.01 & 1.01 & 1.01 \\
$A_{3 j}$ & 1.93 & 2.87 & 4.75 & 2.87 & 1.93 & 1.46 & 1.09 & 1.04 & 1.01 & 1.01 \\
$A_{4 j}$ & 1.44 & 1.89 & 2.79 & 4.58 & 2.79 & 1.89 & 1.44 & 1.08 & 1.04 & 1.01 \\
$A_{5 j}$ & 1.08 & 1.44 & 1.88 & 2.77 & 4.55 & 2.77 & 1.88 & 1.44 & 1.08 & 1.04 \\
$A_{6 j}$ & 1.04 & 1.08 & 1.44 & 1.88 & 2.77 & 4.55 & 2.77 & 1.88 & 1.44 & 1.08 \\
$A_{7 j}$ & 1.01 & 1.04 & 1.08 & 1.44 & 1.89 & 2.79 & 4.58 & 2.79 & 1.89 & 1.44 \\
$A_{8 j}$ & 1.01 & 1.01 & 1.04 & 1.09 & 1.46 & 1.93 & 2.87 & 4.75 & 2.87 & 1.93 \\
$A_{9 j}$ & 1.01 & 1.01 & 1.01 & 1.05 & 1.10 & 1.51 & 2.03 & 3.06 & 5.13 & 3.06 \\
$A_{10 j}$ & 1.01 & 1.01 & 1.01 & 1.01 & 1.06 & 1.13 & 1.65 & 2.30 & 3.60 & 6.21
\end{tabular}

\section{$5 \quad$ Results}

Before we examine the upward mobility measure, we report a Shorrocks measure of overall income mobility, $\mathcal{M}_{s}(\mathbf{P})$ (see (9)), which is an average, across all income classes, of the probabilities of an individual moving out of their current income class. Shorrocks' measure is simply the sum of upward and downward mobility (see Gang et al. (2003) for details). As an instrumental measure to study glass ceiling, we also report our measure of upward mobility, $\mathcal{M}_{U}$. We report both measures for the full sample and we report $\mathcal{M}_{U}$ for low, middle and high sub-groups of the income classes.

Champernowne (1953) suggests that, except for the first and last income classes, all income classes should be equal in log length. In this spirit, we divide real incomes for the United States and Germany into ten income classes, whose definitions are given in Table 4 below. The first and tenth income class were designed to approximately contain the bottom five percent and top five percent of the income distribution respectively. The other thresholds divide the intervening distribution into income ranges equal in log length. The boundaries for each classification are fixed in terms of 1991 U.S. dollars and are not a function of the data. 
An alternative approach would be to define the income classes to represent certain percentiles of the data or, in other words, to have the definition of the income classes be based on the order statistic. We do not follow this approach as defining the boundaries using the order statistic can generate "phantom" transitions (Durlauf and Quah 1999). Consider the case of an individual, $i$, whose income decreases so that they move down $s$ places in the order distribution. As a consequence, the $s$ individuals immediately below individual $i$ will move up one place in the order distribution, even if their income has not changed. This is not the definition of upward income mobility that we employ in this paper. Upward income mobility is defined here as an increase in real income and not a movement up the real income order distribution.

Table 4: Income Class Definitions: 1991 Constant US Dollar

\begin{tabular}{ccc} 
Income Class & Income Range & Sub-Group \\
\hline 1 & {$[0,10000)$} & Low \\
2 & {$[10000,12375)$} & Low \\
3 & {$[12375,15314)$} & Low \\
4 & {$[15314,18951)$} & Middle \\
5 & {$[18951,23452)$} & Middle \\
6 & {$[23452,29022)$} & Middle \\
7 & {$[29022,35915)$} & High \\
8 & {$[35915,44444)$} & High \\
9 & {$[44444,55000)$} & High \\
10 & {$[55000, \infty)$} & High
\end{tabular}

The definition of the transition length is chosen to be five years as we have explained in previous section. The results for both Germany and the United States are reported below. Tables A.1 to A.4 contain the posterior means and standard deviations for the initial distribution, the transition matrix and the invariant distribution for both men and women in the United States and in Germany. The reported number of observed transitions count the total number of transitions observed and may include multiple observations of one individual. 
With respect to the initial distribution, the results for the United States and Germany are quite similar. ${ }^{12}$ The initial income distribution for men is to the right of the initial income distribution for women in both the United States and in Germany. That is, the proportion of women in the low income classes (income classes 1 through 4 ) is significantly higher than the proportion of men while the proportion of men in the high income classes (income classes 6 through 10) is significantly higher than the proportion of women. Therefore, it appears that the men have higher initial income than women in both the United States and Germany.

The invariant distributions of men and women in the two countries, reported in Tables A.1 to A.4, are the limiting income distributions that are implied by the estimated transition matrices, $\mathbf{P}$. It is clear that for both countries and for both men and women that the invariant distribution has shifted to the right of the initial distribution. In both the United States and in Germany, the proportion of men in the highest three income classes is significantly bigger than the proportion of women in those same income classes. Therefore, there still appears to be a gap between male and female income distribution, even in the limit.

The differences between the initial and limiting income distribution, while giving some indication of the overall movements in the income distribution, do not shed light on the differences in income mobility between men and women. We therefore report various mobility indices for men and women in the United States and in Germany. Posterior means and standard deviations (in parentheses) are reported in Table 5 below.

The results are quite stark. In both the United States and Germany, men have a higher average probability of moving to a higher income class than women. In the United States, men have, on average, a 0.5024 probability of moving to a higher income class while women have a 0.4195 probability of moving to a higher income class. This equates

\footnotetext{
${ }^{12}$ The initial income distribution refers to the income distribution for 1984, the first year of our sample.
} 
Table 5: Mobility Indices (1984-1996): United States and Germany Mobility Index Group Men Women Premium for Men $\operatorname{Prob}\left(\mathcal{S}_{M}>\mathcal{S}_{F}\right)$

\section{United States}

$\begin{array}{cccccc}\mathcal{M}_{S} & \text { All } & 0.7462 & 0.7112 & 1.0499 & 0.9470 \\ & & (0.0122) & (0.0184) & (0.0323) & \\ \mathcal{M}_{U} & \text { All } & 0.5024 & 0.4195 & 1.1991 & 1.0000 \\ & & (0.0123) & (0.0161) & (0.0540) & \\ \mathcal{M}_{U} \mid c & \text { Low } & 0.6735 & 0.5795 & 1.1645 & 0.9920 \\ & & (0.0283) & (0.0269) & (0.0722) & \\ \mathcal{M}_{U} \mid c & \text { Middle } & 0.4889 & 0.4110 & 1.1927 & 0.9960 \\ & & (0.0172) & (0.0214) & (0.0731) & \\ \mathcal{M}_{U} \mid c & \text { High } & 0.2585 & 0.2011 & 1.3056 & 0.9790 \\ & & (0.0134) & (0.0246) & (0.1784) & \end{array}$

\section{Germany}

$\begin{array}{cccccc}\mathcal{M}_{S} & \text { All } & 0.6726 & 0.7159 & 0.9405 & 0.0530 \\ & & (0.0120) & (0.0231) & (0.0349) & \\ \mathcal{M}_{U} & \text { All } & 0.4954 & 0.4275 & 1.1612 & 0.9970 \\ & & (0.0115) & (0.0192) & (0.0584) & \\ \mathcal{M}_{U} \mid c & \text { Low } & 0.6696 & 0.5850 & 1.1482 & 0.9750 \\ & & (0.0288) & (0.0318) & (0.0797) & \\ \mathcal{M}_{U} \mid c & \text { Middle } & 0.4787 & 0.4445 & 1.0798 & 0.9080 \\ & & (0.0105) & (0.0226) & (0.0610) & \\ \mathcal{M}_{U} \mid c & \text { High } & 0.2534 & 0.1897 & 1.3719 & 0.9670 \\ & & (0.0123) & (0.0307) & (0.2417) & \end{array}$

to men having approximately a $20 \%$ premium over women in upward income mobility. In Germany, men have a $16 \%$ premium over women in upward income mobility $(0.4954$ to 0.4275$)$.

When we compute the upward mobility measures for the low, middle and high income groups we see a similar pattern. In all groups, men have a higher probability than women of moving to a higher income class. In particular, in the United States, men have a 16\%, $19 \%$, and a $29 \%$ premium in upward income mobility over women in the low, middle and 
high income groups, respectively. These differences are significant in that in all cases the posterior probability that men have a higher upward mobility than women is greater than 0.979. The German results are similar to those of the United States. In Germany, men have approximately a $14.5 \%$, an $8 \%$ and a $33.5 \%$ premium in upward income mobility over women in the low, middle and high income groups respectively. These results are also significant in that the posterior probability that men have an higher upward mobility measure than women is greater than 0.908 in all cases. Moreover, as can be seen from Figures B.1 to B.4 in the Appendices, the distribution of the mobility measures for men and women have little overlap.

Formal comparisons of differences between men and women in the mobility indices between the United States and Germany can be found in the Appendices. Figures B.5 and B.6 show the comparison of the posterior distribution of the gender difference in mobility indices between the United States and Germany. Table A.5 reports the posterior probability that the gender difference in the mobility measure for the United States is greater than the equivalent measure in Germany. The differences in overall mobility are the biggest with a 0.992 probability that the difference between men and women in the United States in bigger than the difference between men and women in Germany. With regard to gender differences in the upward mobility measures, the biggest difference between the United States and Germany is the gender difference in upward mobility for the middle income group. In all other cases the gap between the two countries is negligible.

Overall the results strongly show that men have a greater probability of moving up in the income distribution. This result holds across all income classes with the highest percentage differences between men and women occurring in the highest income group. This suggests that we cannot reject the glass ceiling hypothesis for women at all levels of income. While we see the biggest proportionate difference in upper income mobility between men and women in the higher incomes we also see substantial differences in the 
low and middle incomes. This result contrasts with the conventional concept that women face a glass ceiling at the upper end of the job ladder.

\section{Conclusion}

The glass ceiling hypothesis highlights the belief that the playing field is level for women and men in the labor market up to a point, after which there is an effective limit on advancement for women. If there is a glass ceiling, we may expect that the upward income mobility of women is limited in comparison to men's, i.e., women become trapped.

We are particularly interested in whether or not a glass ceiling exists in Germany and the United States. In order to study the glass ceiling, we modelled the dynamics of the income distribution of a country as a finite state first order Markov chain, using data from Germany and the United States. We estimated this model for each country using Bayesian methods with a neutral prior that was designed to reflect relative uncertainty on behalf of the researcher. Once estimated we then were able to analyze the income mobility properties of the data. In particular, we analyzed the upward income mobility characteristics of the data with respect to men and women.

Glass ceiling stories largely arise amongst discussions of "career-oriented" women. We defined the concept of the "career-oriented" women and contrasted their movements with similar "career-oriented" men. We studied where women and men are located in the real income distribution and the change in this position over time. Our study of the labor income mobility of men and women in Germany and the United States employed the Cross-National Equivalent File, drawn from the PSID for the United States and the German Socio-Economic Panel.

We found strong evidence that, in both the United States and Germany, women have significantly lower upward income mobility than men. This result was consistent across 
the broad income sub-groups that we defined. We find that the largest proportionate differences in upward income mobility are in the higher incomes but there are substantial differences in the lower incomes as well. The first result is evidence in favor of the standard glass ceiling hypothesis: women face lower upward income mobility once they reach the upper end of the income distribution. The second result, that lower income mobility is also present in the lower incomes, suggests the glass ceiling is present there as well. Glass ceilings at lower income levels may result from lower income groups containing, among others, young people at the start of their careers. Lower upward income mobility in the lower income groups could be due to women facing a glass ceiling, or at least larger impediments to income increases, throughout their entire careers. 


\section{References}

Albrecht, J., A. Björklund, and S. Vroman (2003) 'Is there a glass ceiling in Sweden?' Journal of Labor Economics 21(1), 145-177

Athey, S., C. Avery, and P. Zemksy (2000) 'Mentoring and diversity.' American Economic Review 90(4), 765-786

Booth, A.L., M. Francesconi, and J. Frank (2003) 'A sticky floors model of promotion, pay and gender.' Forthcoming in European Economic Review

Buchinsky, M., and J. Hunt (1999) 'Wage mobility in the United States.' Review of Economics and Statistics 81(3), 351-368

Champernowne, D. G. (1953) 'A model of income distribution.' Economic Journal 63(250), 318-351

Devroye, L. (1986) Non-uniform Random Variate Generation (New York:SpringerVerlag)

Duleep, H. O., and S. Sanders (1992) 'Discrimination at the top: American-born Asian and white men.' Industrial Relations 31(3), 416-432

Durlauf, S. N., and D. T. Quah (1999) 'The new empirics of economic growth.' In Handbook of Macroeconomics, ed. John B. Taylor and Michael Woodford (North-Holland Elsevier Science) chapter 4, pp. 231-304

Gang, I., J. Landon-Lane, and M.-S. Yun (2003) 'Modelling upward income mobility: Theory and applications.' mimeo

Geweke, J. F., C. Marshall, and G. A. Zarkin (1986) 'Mobility indices in continuous time Markov chains.' Econometrica 54, 1407-1423 
Good for Business: Making Full Sense of the Nation's Human Capital (1995) Report from Glass Ceiling Commission, Department of Labor, Washington D.C.

McDowell, J. M., Jr. L. D. Singell, and J. P. Ziliak (1999) 'Cracks in the glass ceiling: Gender and promotion in the economics profession.' American Economic Review 89(2), 392-396

Ransom, M., and R. L. Oaxaca (2003) 'Intrafirm mobility and sex differences in pay.' IZA Discussion Paper 704

Shorrocks, A. F. (1976) 'Income mobility and the Markov assumption.' Economic Journal $86,566-578$ (1978) 'The measurement of mobility.' Econometrica 46, 1013-1024 


\section{A Tables}

Table A.1: Posterior Moments: United States' Men (5 year transition)

\begin{tabular}{|c|c|c|c|c|c|c|c|c|c|}
\hline \multicolumn{10}{|c|}{ Income Class } \\
\hline 1 & 2 & 3 & 4 & 5 & 6 & 7 & 8 & 9 & 10 \\
\hline \multicolumn{10}{|c|}{ Initial distribution } \\
\hline $\begin{array}{c}0.0508 \\
(0.0081)\end{array}$ & $\begin{array}{c}0.0432 \\
(0.0074)\end{array}$ & $\begin{array}{c}0.0846 \\
(0.0106)\end{array}$ & $\begin{array}{c}0.1127 \\
(0.0119)\end{array}$ & $\begin{array}{c}0.1257 \\
(0.0122)\end{array}$ & $\begin{array}{c}0.1623 \\
(0.0135)\end{array}$ & $\begin{array}{c}0.1302 \\
(0.0128)\end{array}$ & $\begin{array}{c}0.1316 \\
(0.0125)\end{array}$ & $\begin{array}{c}0.0756 \\
(0.0097)\end{array}$ & $\begin{array}{c}0.0833 \\
(0.0102)\end{array}$ \\
\hline
\end{tabular}

Transition Matrix: P

$\begin{array}{cccccccccc}0.3148 & 0.2017 & 0.1375 & 0.1368 & 0.0923 & 0.0521 & 0.0137 & 0.0131 & 0.0129 & 0.0250 \\ (0.0527) & (0.0425) & (0.0381) & (0.0379) & (0.0300) & (0.0230) & (0.0129) & (0.0127) & (0.0127) & (0.0170) \\ 0.1081 & 0.1726 & 0.1985 & 0.2046 & 0.1382 & 0.0581 & 0.0408 & 0.0400 & 0.0257 & 0.0134 \\ (0.0353) & (0.0447) & (0.0445) & (0.0453) & (0.0379) & (0.0266) & (0.0220) & (0.0219) & (0.0171) & (0.0130) \\ 0.0669 & 0.0979 & 0.2193 & 0.2777 & 0.1686 & 0.0813 & 0.0407 & 0.0209 & 0.0200 & 0.0068 \\ (0.0197) & (0.0241) & (0.0328) & (0.0351) & (0.0299) & (0.0216) & (0.0160) & (0.0117) & (0.0109) & (0.0064) \\ 0.0535 & 0.0300 & 0.1323 & 0.2373 & 0.2679 & 0.1407 & 0.1046 & 0.0149 & 0.0099 & 0.0090 \\ (0.0156) & (0.0120) & (0.0235) & (0.0277) & (0.0295) & (0.0234) & (0.0204) & (0.0078) & (0.0065) & (0.0062) \\ 0.0087 & 0.0247 & 0.0280 & 0.1464 & 0.3045 & 0.2825 & 0.1343 & 0.0394 & 0.0196 & 0.0120 \\ (0.0058) & (0.0092) & (0.0104) & (0.0215) & (0.0288) & (0.0272) & (0.0204) & (0.0116) & (0.0085) & (0.0068) \\ 0.0069 & 0.0106 & 0.0276 & 0.0552 & 0.1547 & 0.3130 & 0.2532 & 0.1185 & 0.0369 & 0.0234 \\ (0.0047) & (0.0058) & (0.0091) & (0.0128) & (0.0198) & (0.0262) & (0.0241) & (0.0184) & (0.0104) & (0.0084) \\ 0.0102 & 0.0105 & 0.0144 & 0.0121 & 0.0636 & 0.1443 & 0.3557 & 0.2765 & 0.0736 & 0.0390 \\ (0.0055) & (0.0057) & (0.0066) & (0.0061) & (0.0141) & (0.0199) & (0.0283) & (0.0251) & (0.0147) & (0.0113) \\ 0.0037 & 0.0076 & 0.0043 & 0.0125 & 0.0359 & 0.0466 & 0.1936 & 0.3696 & 0.2401 & 0.0860 \\ (0.0037) & (0.0052) & (0.0040) & (0.0067) & (0.0115) & (0.0131) & (0.0243) & (0.0301) & (0.0259) & (0.0169) \\ 0.0061 & 0.0057 & 0.0062 & 0.0066 & 0.0082 & 0.0107 & 0.0736 & 0.1942 & 0.3697 & 0.3189 \\ (0.0060) & (0.0058) & (0.0059) & (0.0059) & (0.0068) & (0.0081) & (0.0193) & (0.0295) & (0.0359) & (0.0356) \\ 0.0114 & 0.0062 & 0.0115 & 0.0068 & 0.0184 & 0.0377 & 0.0452 & 0.0747 & 0.1605 & 0.6277 \\ (0.0079) & (0.0064) & (0.0081) & (0.0065) & (0.0099) & (0.0143) & (0.0152) & (0.0192) & (0.0264) & (0.0353)\end{array}$

Invariant Distribution

$\begin{array}{cccccccccc}0.0211 & 0.0213 & 0.0337 & 0.0558 & 0.0917 & 0.1137 & 0.1571 & 0.1675 & 0.1443 & 0.1938 \\ (0.0046) & (0.0040) & (0.0051) & (0.0070) & (0.0093) & (0.0106) & (0.0117) & (0.0128) & (0.0140) & (0.0221)\end{array}$

Observed Transitions: $\quad 1783$ 
Table A.2: Posterior Moments: United States' Women (5 year transition)

\begin{tabular}{|c|c|c|c|c|c|c|c|c|c|}
\hline \multicolumn{10}{|c|}{ Income Class } \\
\hline 1 & 2 & 3 & 4 & 5 & 6 & 7 & 8 & 9 & 10 \\
\hline \multicolumn{10}{|c|}{ Initial distribution } \\
\hline $\begin{array}{c}0.0687 \\
(0.0139)\end{array}$ & $\begin{array}{c}0.1207 \\
(0.0172)\end{array}$ & $\begin{array}{c}0.1272 \\
(0.0185)\end{array}$ & $\begin{array}{c}0.2181 \\
(0.0225)\end{array}$ & $\begin{array}{c}0.1329 \\
(0.0178)\end{array}$ & $\begin{array}{c}0.1304 \\
(0.0181)\end{array}$ & $\begin{array}{c}0.0824 \\
(0.0141)\end{array}$ & $\begin{array}{c}0.0454 \\
(0.0106)\end{array}$ & $\begin{array}{c}0.0370 \\
(0.0098)\end{array}$ & $\begin{array}{c}0.0373 \\
(0.0100)\end{array}$ \\
\hline \multicolumn{10}{|c|}{ Transition Matrix: $\mathrm{P}$} \\
\hline $\begin{array}{c}0.4134 \\
(0.0504)\end{array}$ & $\begin{array}{c}0.2175 \\
(0.0411)\end{array}$ & $\begin{array}{c}0.1219 \\
(0.0328)\end{array}$ & $\begin{array}{c}0.1082 \\
(0.0309)\end{array}$ & $\begin{array}{c}0.0433 \\
(0.0203)\end{array}$ & $\begin{array}{c}0.0445 \\
(0.0203)\end{array}$ & $\begin{array}{c}0.0200 \\
(0.0133)\end{array}$ & $\begin{array}{c}0.0106 \\
(0.0102)\end{array}$ & $\begin{array}{c}0.0102 \\
(0.0100)\end{array}$ & $\begin{array}{c}0.0104 \\
(0.0104)\end{array}$ \\
\hline 0.1626 & 0.2259 & 0.3039 & 0.1151 & 0.0917 & 0.0221 & 0.0298 & 0.0301 & 0.0091 & 0.0099 \\
\hline$(0.0360)$ & $(0.0416)$ & $(0.0459)$ & $(0.031)$ & $(0.0270)$ & $(0.0145)$ & $(0.0166)$ & $(0.0161)$ & $(0.0089)$ & $(0.0095)$ \\
\hline 0.0523 & 0.0827 & 0.3244 & 0.2722 & 0.164 & 0.0613 & 0.0143 & 0.0142 & 0.0072 & 0.0069 \\
\hline$(0.0179)$ & $(0.0224)$ & $(0.0363)$ & $(0.03$ & $(0.029$ & $(0.0195)$ & $(0.010$ & $(0.00$ & $(0.0071)$ & $(0.0067)$ \\
\hline 0.0182 & 0.0419 & 0.1421 & 0.316 & 0.2863 & 0.1206 & 0.0451 & 0.0114 & 0.0060 & 0.0116 \\
\hline$(0.0097)$ & $(0.0143)$ & $(0.0253)$ & $(0.0326)$ & $(0.0329)$ & $(0.0230)$ & $(0.0148)$ & $(0.0075)$ & $(0.0058)$ & $(0.0078)$ \\
\hline 0.0071 & 0.0250 & 0.0499 & 0.1104 & 0.3718 & 0.3027 & 0.1066 & 0.0136 & 0.0071 & 0.0060 \\
\hline$(0.0061)$ & $(0.0121)$ & $(0.0161)$ & $(0.0233)$ & $(0.0361)$ & $(0.0347)$ & $(0.0236)$ & $(0.0088)$ & $(0.0065)$ & $(0.0056)$ \\
\hline 0.0075 & 0.0078 & 0.0145 & 0.0434 & 0.1838 & 0.4270 & 0.2153 & 0.0704 & 0.0223 & 0.0080 \\
\hline$(0.0074)$ & $(0.0071)$ & $(0.0091)$ & $(0.0166)$ & $(0.0310)$ & $(0.0398)$ & $(0.0331)$ & $(0.0200)$ & $(0.0123)$ & $(0.0072)$ \\
\hline 0.0089 & 0.0090 & 0.0100 & 0.0360 & 0.0576 & 0.1122 & 0.4599 & 0.2213 & 0.0567 & 0.0283 \\
\hline$(0.0083)$ & $(0.0085)$ & $(0.0094)$ & $(0.0170)$ & $(0.0208)$ & $(0.0278)$ & $(0.0446)$ & $(0.0381)$ & $(0.0214)$ & $(0.0154)$ \\
\hline 0.0176 & 0.0195 & 0.0203 & 0.0214 & 0.0434 & 0.0887 & 0.1741 & 0.3250 & 0.1883 & 0.1016 \\
\hline$(0.0171)$ & $(0.0181)$ & $(0.0196)$ & $(0.0189)$ & $(0.0271)$ & $(0.0388)$ & $(0.0508)$ & $(0.0607)$ & $(0.0524)$ & $(0.0404)$ \\
\hline 0.0266 & 0.0298 & 0.0283 & 0.0299 & 0.0321 & 0.0954 & 0.1045 & 0.1585 & 0.2869 & 0.2081 \\
\hline$(0.0265)$ & & $(0.0268)$ & $(0.0274)$ & $(0.0279)$ & $(0.0466)$ & $(0.0505)$ & $(0.0632)$ & $(0.0732)$ & $(0.0668)$ \\
\hline 0.0308 & 0.0306 & 0.0325 & 0.0346 & 0.0370 & 0.0404 & 0.0794 & 0.1012 & 0.1653 & 0.4482 \\
\hline$(0.0288)$ & $(0.0281)$ & $(0.0307)$ & $(0.0338)$ & $(0.0348)$ & $(0.0343)$ & $(0.0483)$ & $(0.0557)$ & $(0.0623)$ & $(0.0859)$ \\
\hline
\end{tabular}

Invariant Distribution

$\begin{array}{cccccccccc}0.0371 & 0.0401 & 0.0721 & 0.0965 & 0.1549 & 0.1814 & 0.1747 & 0.1104 & 0.0680 & 0.0647 \\ (0.0087) & (0.0078) & (0.0105) & (0.0126) & (0.0167) & (0.0186) & (0.0209) & (0.0166) & (0.0143) & (0.0174)\end{array}$

Observed Transitions: $\quad 927$ 
Table A.3: Posterior Moments: German Men (5 year transition)

\begin{tabular}{|c|c|c|c|c|c|c|c|c|c|}
\hline \multicolumn{10}{|c|}{ Income Class } \\
\hline 1 & 2 & 3 & 4 & 5 & 6 & 7 & 8 & 9 & 10 \\
\hline \multicolumn{10}{|c|}{ Initial distribution } \\
\hline $\begin{array}{c}0.0269 \\
(0.0043)\end{array}$ & $\begin{array}{c}0.0320 \\
(0.0044)\end{array}$ & $\begin{array}{c}0.0764 \\
(0.0069)\end{array}$ & $\begin{array}{c}0.1915 \\
(0.0103)\end{array}$ & $\begin{array}{c}0.2226 \\
(0.0102)\end{array}$ & $\begin{array}{c}0.1823 \\
(0.0098)\end{array}$ & $\begin{array}{c}0.1178 \\
(0.0079)\end{array}$ & $\begin{array}{c}0.0604 \\
(0.0061)\end{array}$ & $\begin{array}{c}0.0429 \\
(0.0051)\end{array}$ & $\begin{array}{c}0.0472 \\
(0.0053)\end{array}$ \\
\hline
\end{tabular}

Transition Matrix: P

$\begin{array}{cccccccccc}0.3557 & 0.1861 & 0.1492 & 0.0831 & 0.0821 & 0.0560 & 0.0207 & 0.0336 & 0.0168 & 0.0166 \\ (0.0580) & (0.0490) & (0.0450) & (0.0351) & (0.0354) & (0.0295) & (0.0176) & (0.0230) & (0.0164) & (0.0160) \\ 0.1000 & 0.2535 & 0.1934 & 0.1360 & 0.1784 & 0.0625 & 0.0319 & 0.0161 & 0.0144 & 0.0138 \\ (0.0341) & (0.0503) & (0.0439) & (0.0385) & (0.0436) & (0.0274) & (0.0198) & (0.0155) & (0.0135) & (0.0134) \\ 0.0325 & 0.0540 & 0.1954 & 0.3529 & 0.1936 & 0.1048 & 0.0363 & 0.0073 & 0.0122 & 0.0110 \\ (0.0133) & (0.0162) & (0.0280) & (0.0346) & (0.0283) & (0.0230) & (0.0139) & (0.0064) & (0.0079) & (0.0075) \\ 0.0056 & 0.0097 & 0.0502 & 0.3315 & 0.4339 & 0.1276 & 0.0299 & 0.0028 & 0.0053 & 0.0035 \\ (0.0030) & (0.0039) & (0.0089) & (0.0191) & (0.0201) & (0.0133) & (0.0068) & (0.0020) & (0.0029) & (0.0024) \\ 0.0074 & 0.0095 & 0.0153 & 0.0976 & 0.4273 & 0.3193 & 0.0882 & 0.0239 & 0.0043 & 0.0071 \\ (0.0027) & (0.0033) & (0.0041) & (0.0103) & (0.0167) & (0.0155) & (0.0094) & (0.0053) & (0.0022) & (0.0027) \\ 0.0045 & 0.0060 & 0.0071 & 0.0337 & 0.1244 & 0.4339 & 0.2908 & 0.0696 & 0.0214 & 0.0087 \\ (0.0024) & (0.0028) & (0.0029) & (0.0063) & (0.0120) & (0.0170) & (0.0164) & (0.0092) & (0.0053) & (0.0035) \\ 0.0057 & 0.0025 & 0.0087 & 0.0184 & 0.0269 & 0.1081 & 0.4588 & 0.2870 & 0.0577 & 0.0263 \\ (0.0031) & (0.0021) & (0.0040) & (0.0057) & (0.0067) & (0.0134) & (0.0216) & (0.0190) & (0.0098) & (0.0068) \\ 0.0071 & 0.0039 & 0.0047 & 0.0092 & 0.0180 & 0.0431 & 0.1234 & 0.4524 & 0.2508 & 0.0872 \\ (0.0048) & (0.0037) & (0.0039) & (0.0057) & (0.0073) & (0.0117) & (0.0191) & (0.0278) & (0.0241) & (0.0165) \\ 0.0062 & 0.0131 & 0.0133 & 0.0146 & 0.0108 & 0.0281 & 0.0615 & 0.1416 & 0.4063 & 0.3044 \\ (0.0059) & (0.0095) & (0.0088) & (0.0094) & (0.0085) & (0.0130) & (0.0187) & (0.0285) & (0.0373) & (0.0363) \\ 0.0060 & 0.0060 & 0.0065 & 0.0072 & 0.0320 & 0.0406 & 0.0521 & 0.0822 & 0.1353 & 0.6321 \\ (0.0056) & (0.0063) & (0.0061) & (0.0063) & (0.0131) & (0.0146) & (0.0166) & (0.0211) & (0.0253) & (0.0360)\end{array}$

Invariant Distribution

$\begin{array}{cccccccccc}0.0120 & 0.0127 & 0.0181 & 0.0481 & 0.1048 & 0.1413 & 0.1709 & 0.1762 & 0.1388 & 0.1771 \\ (0.0031) & (0.0031) & (0.0031) & (0.0056) & (0.0092) & (0.0104) & (0.0117) & (0.0132) & (0.0131) & (0.0206)\end{array}$

Observed Transitions: $\quad 3360$ 
Table A.4: Posterior Moments: German Women (5 year transition)

\begin{tabular}{|c|c|c|c|c|c|c|c|c|c|}
\hline \multicolumn{10}{|c|}{ Income Class } \\
\hline 1 & 2 & 3 & 4 & 5 & 6 & 7 & 8 & 9 & 10 \\
\hline \multicolumn{10}{|c|}{ Initial distribution } \\
\hline $\begin{array}{c}0.0733 \\
(0.0141)\end{array}$ & $\begin{array}{c}0.0896 \\
(0.0152)\end{array}$ & $\begin{array}{c}0.1808 \\
(0.0205)\end{array}$ & $\begin{array}{c}0.2084 \\
(0.0220)\end{array}$ & $\begin{array}{c}0.1988 \\
(0.0209)\end{array}$ & $\begin{array}{c}0.1045 \\
(0.0158)\end{array}$ & $\begin{array}{c}0.0501 \\
(0.0112)\end{array}$ & $\begin{array}{c}0.0334 \\
(0.0096)\end{array}$ & $\begin{array}{c}0.0305 \\
(0.0093)\end{array}$ & $\begin{array}{c}0.0306 \\
(0.0094)\end{array}$ \\
\hline \multicolumn{10}{|c|}{ Transition Matrix: $\mathrm{P}$} \\
\hline $\begin{array}{c}0.4651 \\
(0.0669)\end{array}$ & $\begin{array}{c}0.1413 \\
(0.0469)\end{array}$ & $\begin{array}{c}0.1228 \\
(0.0419)\end{array}$ & $\begin{array}{c}0.0629 \\
(0.0324)\end{array}$ & $\begin{array}{c}0.0773 \\
(0.0359)\end{array}$ & $\begin{array}{c}0.0380 \\
(0.0247)\end{array}$ & $\begin{array}{c}0.0194 \\
(0.0192)\end{array}$ & $\begin{array}{c}0.0178 \\
(0.0174)\end{array}$ & $\begin{array}{c}0.0374 \\
(0.0244)\end{array}$ & $\begin{array}{c}0.0178 \\
(0.0177)\end{array}$ \\
\hline 0.0917 & 0.2677 & 0.3387 & 0.1501 & 0.0766 & 0.0168 & 0.0154 & 0.0143 & 0.0145 & 0.0143 \\
\hline$(0.0358)$ & $(0.0527)$ & $(0.0558)$ & $(0.0424)$ & $(0.0317)$ & $(0.0157)$ & $(0.0144)$ & $(0.0136)$ & $(0.0148)$ & $(0.0134)$ \\
\hline 0.0457 & 0.1108 & 0.2642 & 0.3452 & 0.1675 & 0.0229 & 0.0219 & 0.0075 & 0.0071 & 0.0072 \\
\hline$(0.0162)$ & $(0.0249)$ & $(0.0353)$ & $(0.0396)$ & $(0.0308)$ & $(0.0123)$ & $(0.0118)$ & $(0.0073)$ & $(0.0070)$ & $(0.0069)$ \\
\hline 0.0235 & 0.0245 & 0.0970 & 0.3334 & 0.4086 & 0.0732 & 0.0225 & 0.0059 & 0.0059 & $\begin{array}{c}0.0054 \\
(0.0052)\end{array}$ \\
\hline$(0.0111)$ & $(0.0112)$ & $(0.0217)$ & $(0.0346)$ & $(0.0367)$ & $(0.0183)$ & $(0.0108)$ & $(0.0056)$ & $(0.0058)$ & $\begin{array}{r}(0.0 \\
0.0\end{array}$ \\
\hline $\begin{array}{c}0.0153 \\
(0.0085)\end{array}$ & $\begin{array}{c}0.0115 \\
(0.0076)\end{array}$ & $\begin{array}{c}0.0217 \\
(0.0101)\end{array}$ & $\begin{array}{c}0.1019 \\
(0.0209)\end{array}$ & $\begin{array}{c}0.4604 \\
(0.0348)\end{array}$ & $\begin{array}{c}0.3168 \\
(0.0337)\end{array}$ & $\begin{array}{c}0.0360 \\
(0.0131)\end{array}$ & $\begin{array}{c}0.0211 \\
(0.0101)\end{array}$ & $\begin{array}{c}0.0054 \\
(0.0051)\end{array}$ & $\begin{array}{c}0.0100 \\
(0.0067)\end{array}$ \\
\hline 0.0155 & 0.0167 & 0.0101 & 0.0278 & 0.0764 & 0.4308 & 0.3613 & 0.0274 & 0.0253 & 0.0089 \\
\hline$(0.0106)$ & $(0.0109)$ & $(0.0087)$ & $(0.0140)$ & $(0.0228)$ & $(0.0429)$ & $(0.0414)$ & $(0.0141)$ & $(0.0135)$ & $(0.0083)$ \\
\hline 0.0157 & 0.0173 & 0.0325 & 0.0357 & 0.0401 & 0.1420 & 0.4210 & 0.1721 & 0.0718 & 0.0519 \\
\hline$(0.0145)$ & $(0.0156)$ & $(0.0217)$ & $(0.0224)$ & $(0.0232)$ & $(0.0438)$ & $(0.0603)$ & $(0.0466)$ & $(0.0309)$ & $(0.0274)$ \\
\hline 0.0350 & 0.0358 & 0.0408 & 0.0396 & 0.0470 & 0.0574 & 0.1170 & 0.3119 & 0.2205 & 0.0951 \\
\hline$(0.0342)$ & $(0.0329)$ & $(0.0383)$ & $(0.0333)$ & $(0.0409)$ & $(0.0429)$ & $(0.0587)$ & $(0.0869)$ & $(0.0754)$ & $(0.0550)$ \\
\hline 0.0415 & 0.0438 & 0.0455 & 0.0482 & 0.0528 & 0.0584 & 0.1122 & 0.1943 & 0.2558 & 0.1476 \\
\hline$(0.0408)$ & $(0.0422)$ & $(0.0435)$ & $(0.0430)$ & $(0.0455)$ & $(0.0475)$ & $(0.0626)$ & $(0.0821)$ & $(0.0869)$ & $(0.0723)$ \\
\hline 0.0464 & 0.0427 & 0.0890 & 0.0464 & 0.0498 & 0.0535 & 0.0631 & 0.0878 & 0.1741 & 0.3471 \\
\hline$(0.0473)$ & $(0.0396)$ & $(0.0612)$ & $(0.0428)$ & $(0.0443)$ & $(0.0433)$ & $(0.0495)$ & $(0.0567)$ & $(0.0788)$ & $(0.0939)$ \\
\hline
\end{tabular}

Invariant Distribution

$\begin{array}{cccccccccc}0.0490 & 0.0456 & 0.0727 & 0.1087 & 0.1744 & 0.1806 & 0.1690 & 0.0843 & 0.0656 & 0.0501 \\ (0.0122) & (0.0093) & (0.0123) & (0.0140) & (0.0194) & (0.0206) & (0.0236) & (0.0187) & (0.0157) & (0.0149)\end{array}$

Observed Transitions:

767 
Table A.5: Comparison of Mobility Measures between the U.S. and Germany

\begin{tabular}{cc} 
Mobility Measure & $\operatorname{prob}\left(\mathcal{M}_{\text {US }}>\mathcal{M}_{\text {Germany }}\right)$ \\
\hline $\mathcal{M}_{S}$ & 0.992 \\
$\mathcal{M}_{U}$ & 0.682 \\
$\mathcal{M}_{U} \mid c($ low $)$ & 0.565 \\
$\mathcal{M}_{U} \mid c($ middle $)$ & 0.890 \\
$\mathcal{M}_{U} \mid c($ high $)$ & 0.430
\end{tabular}




\section{B Figures}

Figure B.1: Mobility Indices: United States

Overall Mobility: $M_{S}$

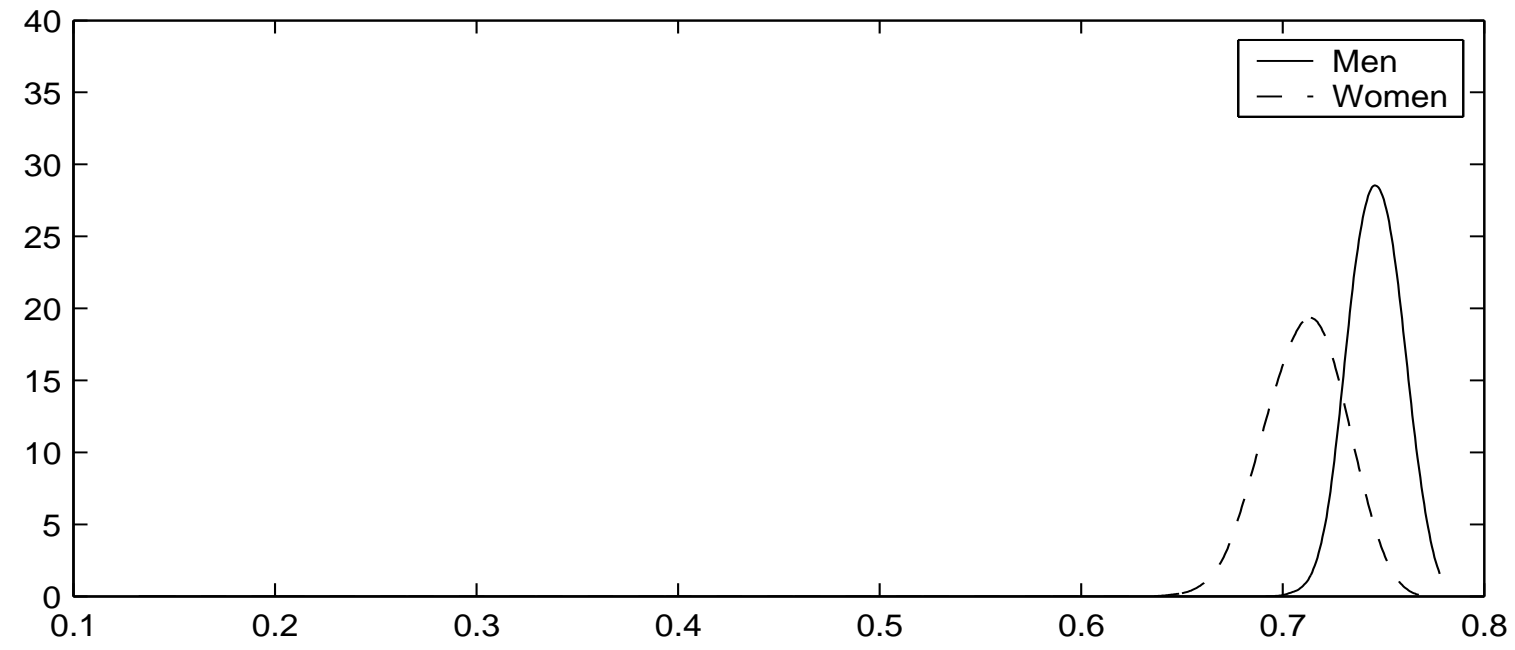

Upward Mobility: $\mathrm{M}_{U}$

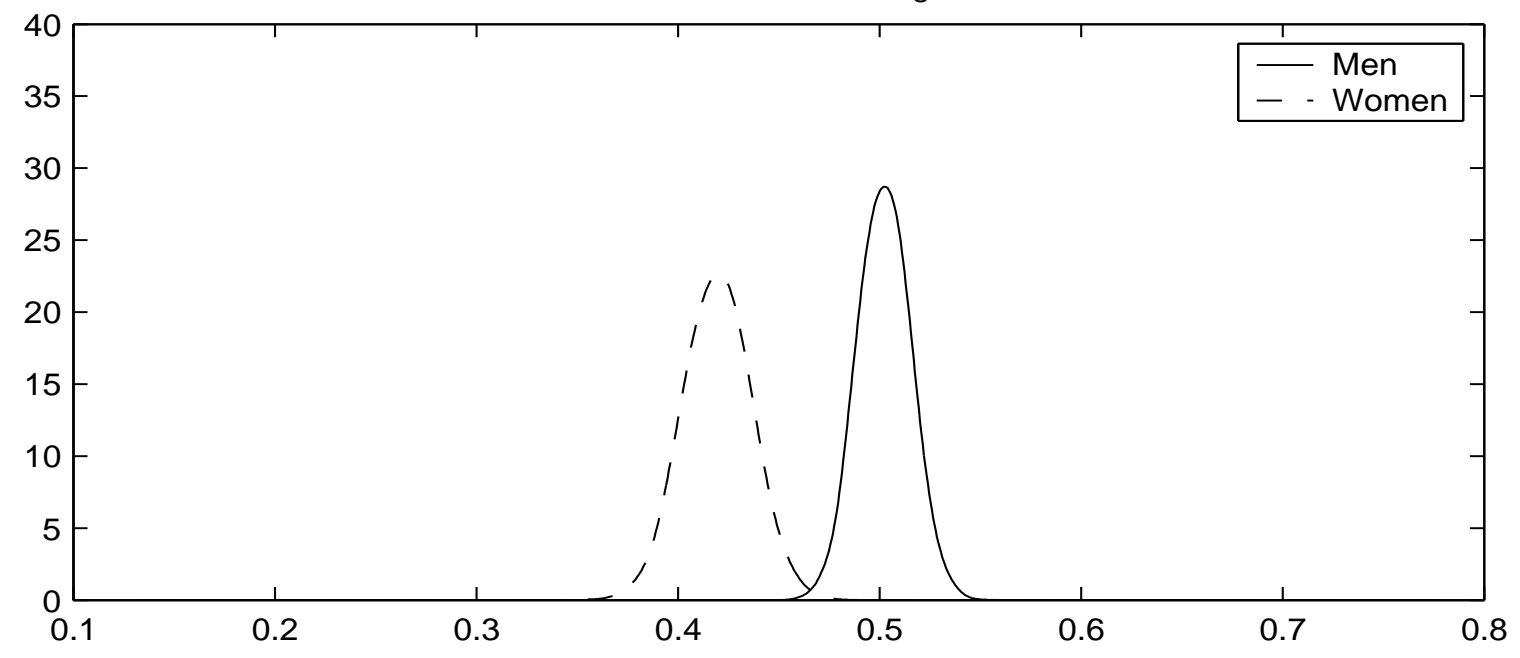


Figure B.2: Conditional Upward Mobility Indices: United States Lower Income Group

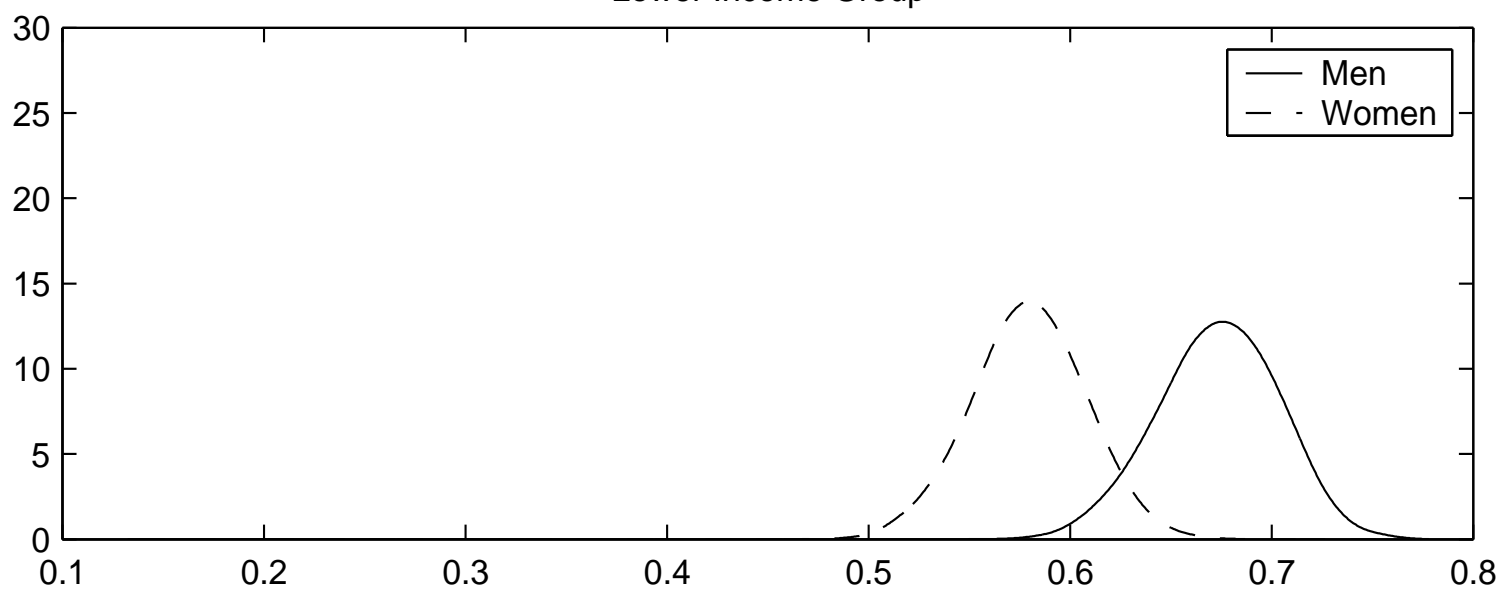

Middle Income Group

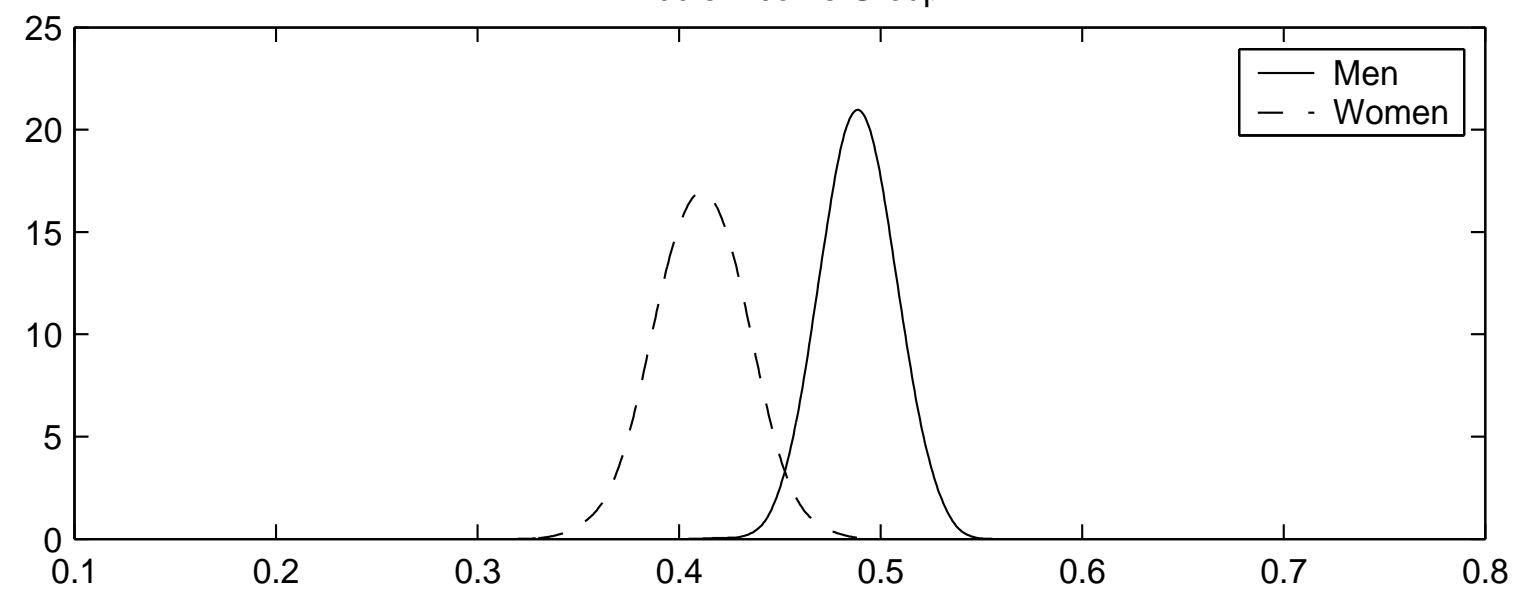

Upper Income Group

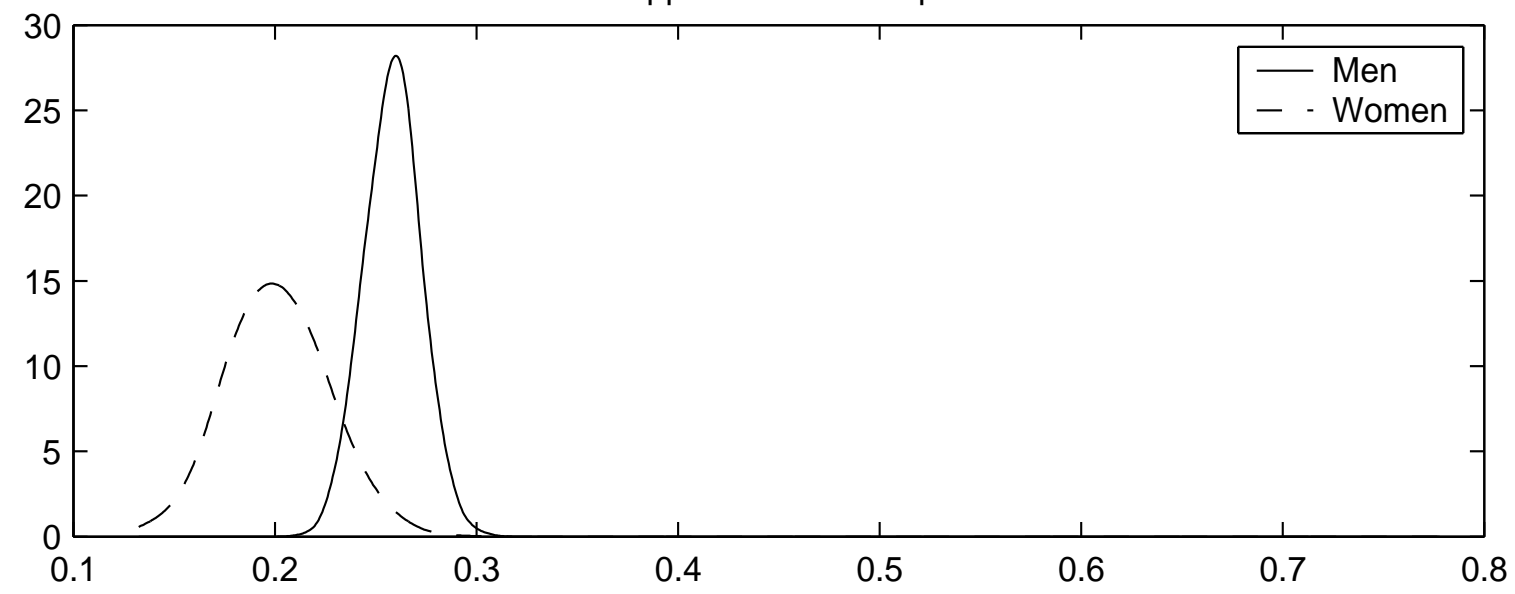


Figure B.3: Mobility Indices: Germany

Overall Mobility: $M_{S}$

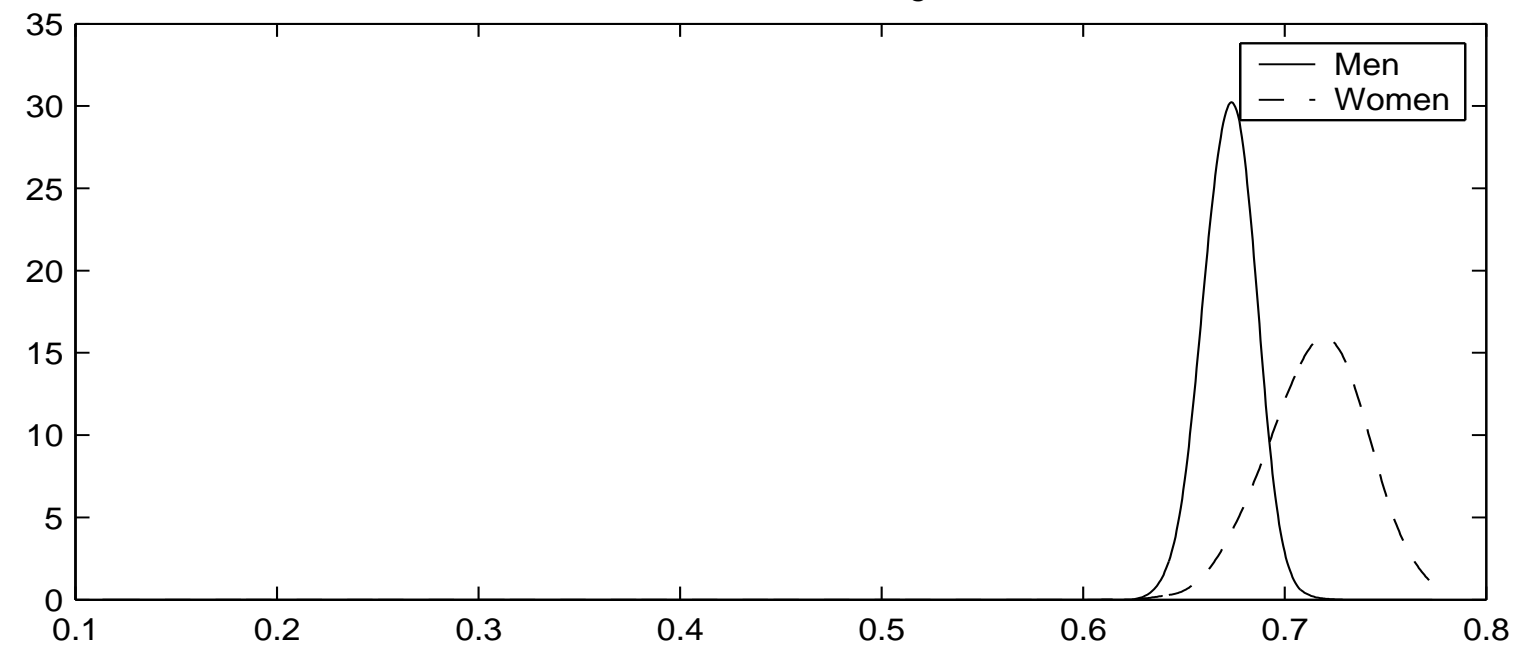

Upward Mobility: $\mathrm{M}_{\mathrm{U}}$

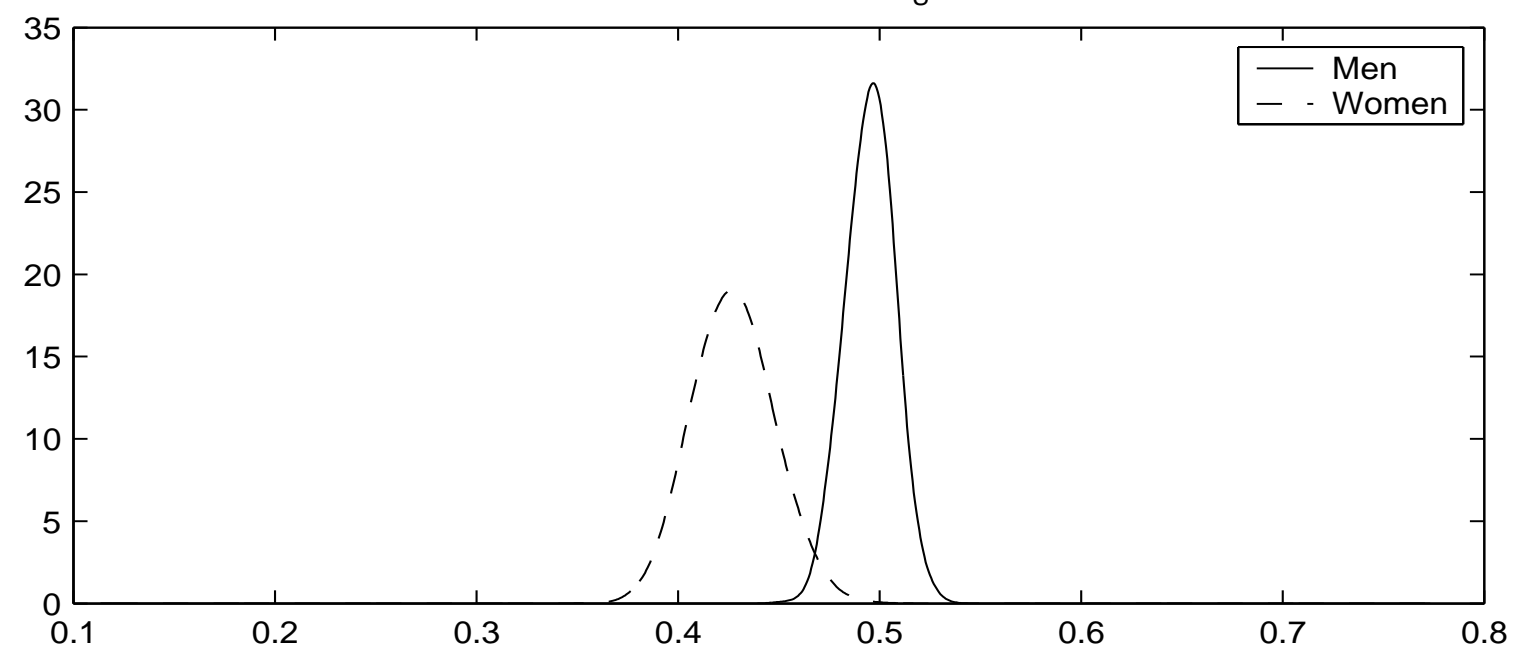


Figure B.4: Conditional Upward Mobility Indices: Germany Lower Income Group

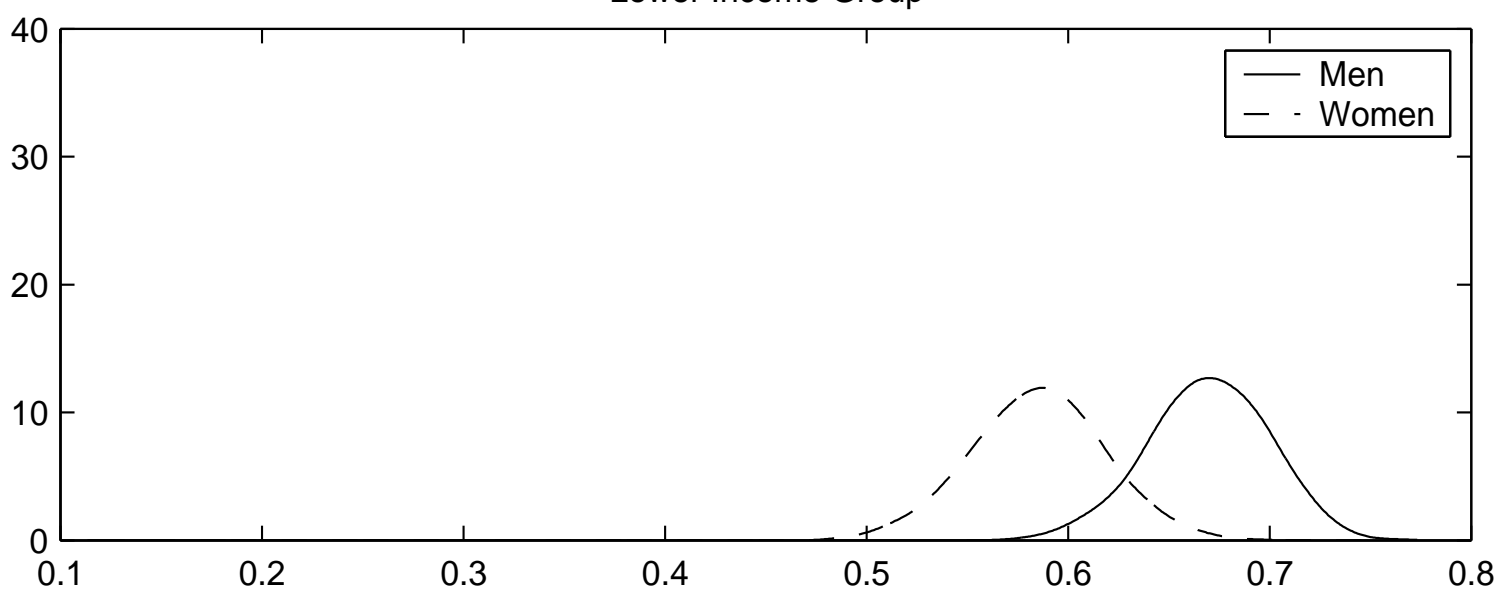

Middle Income Group

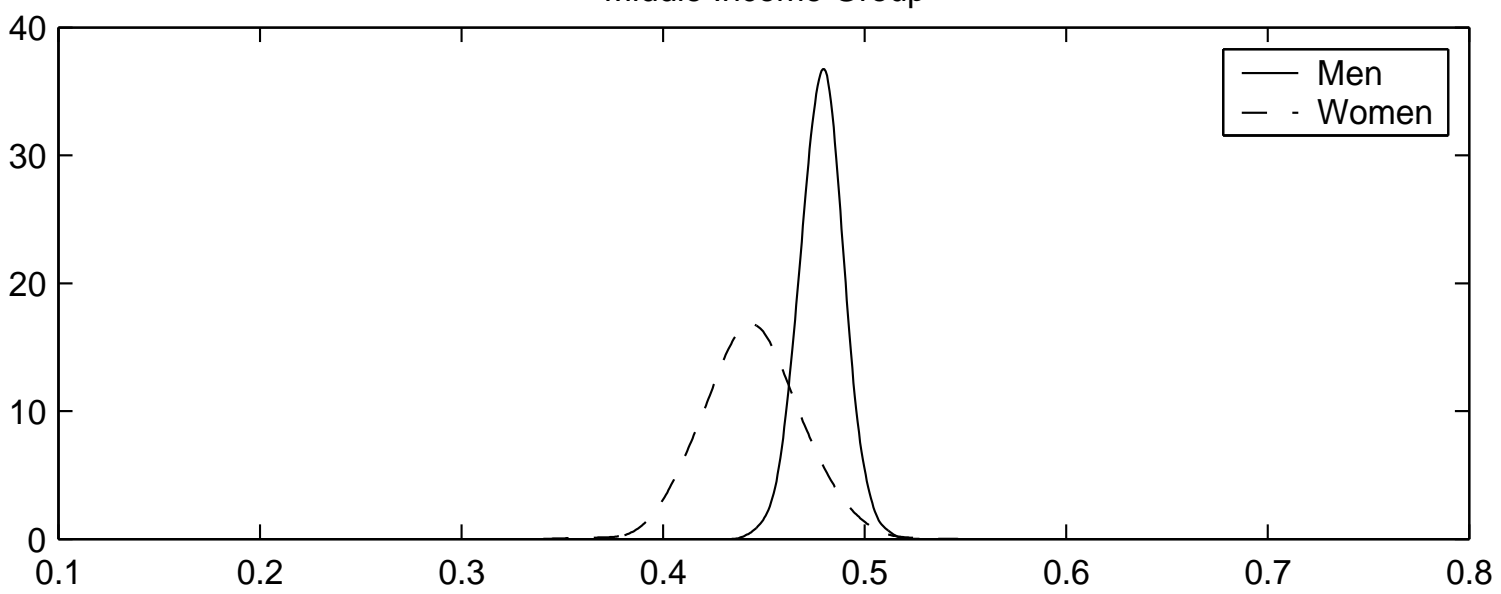

Upper Income Group

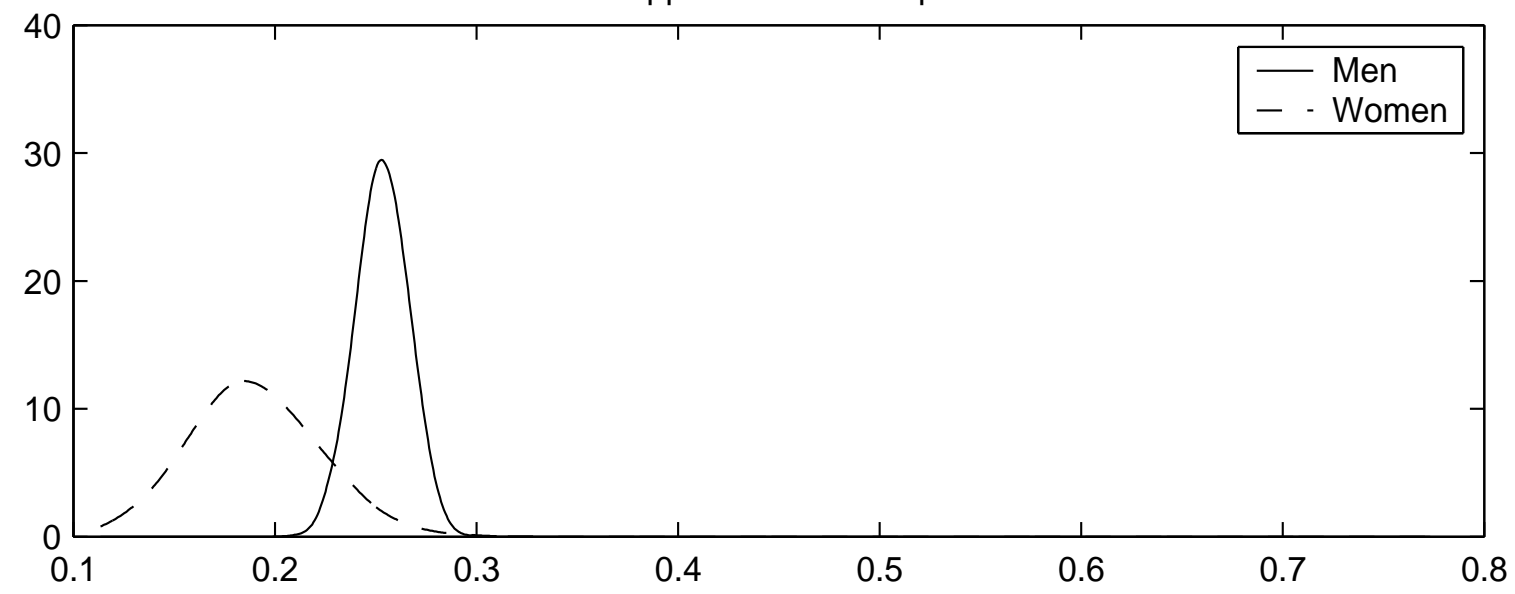


Figure B.5: Comparison of Mobility between the U.S. and Germany Overall Mobility: $\mathrm{M}_{\mathrm{S}}$

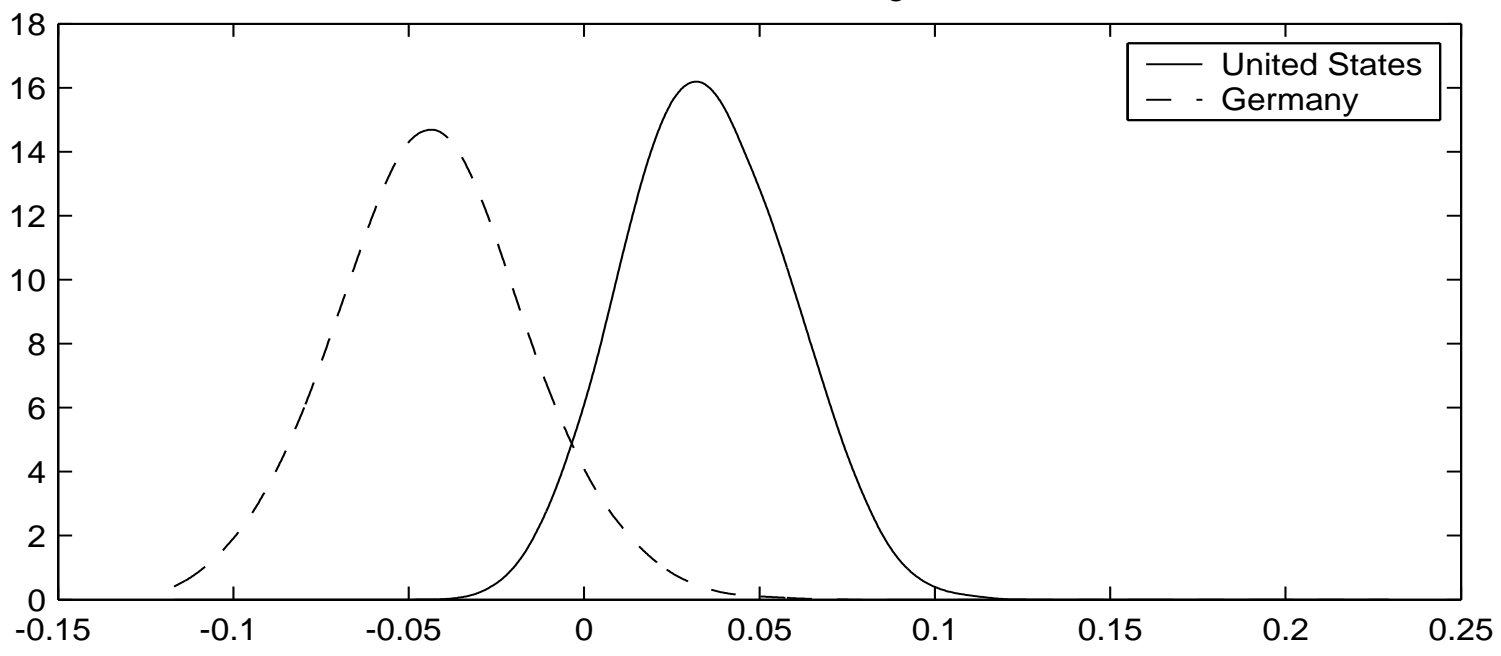

Upward Mobility: $\mathrm{M}_{U}$

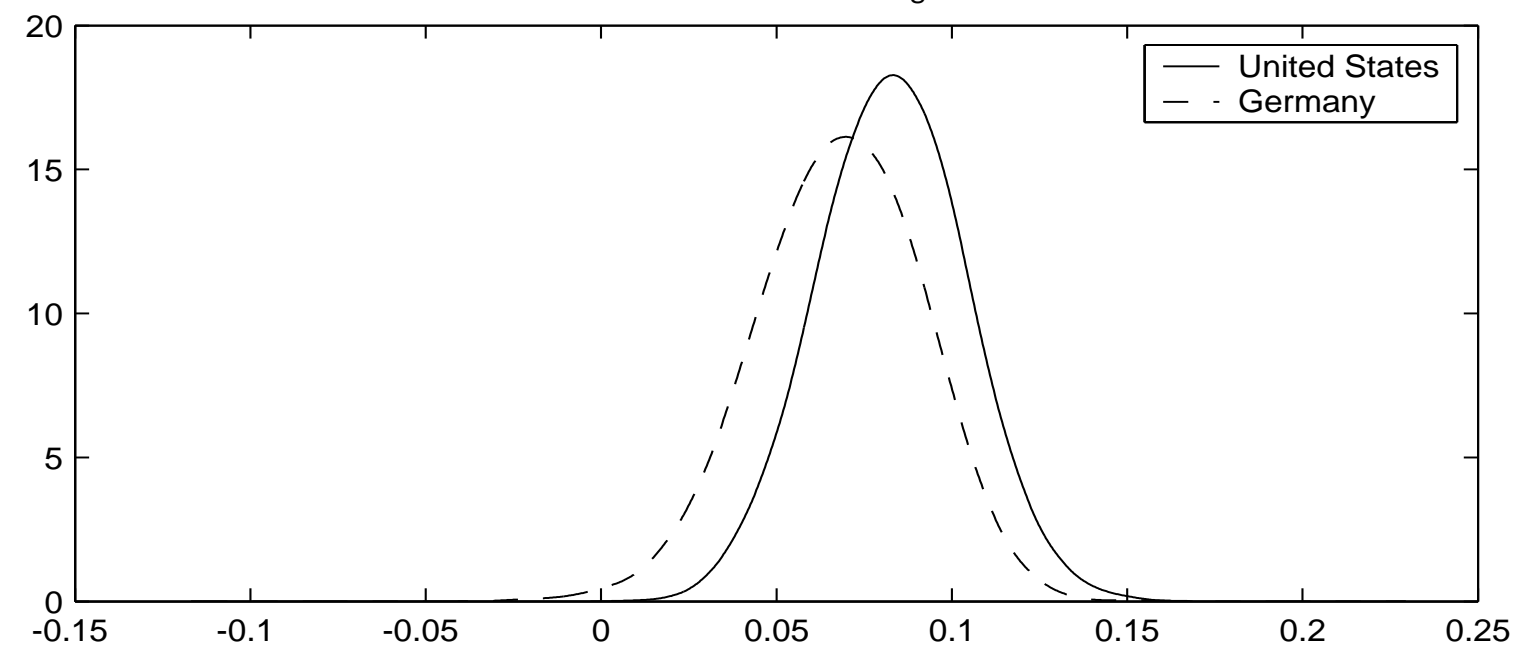


Figure B.6: Comparison of Conditional Mobility between the U.S. and Germany Lower Income Group

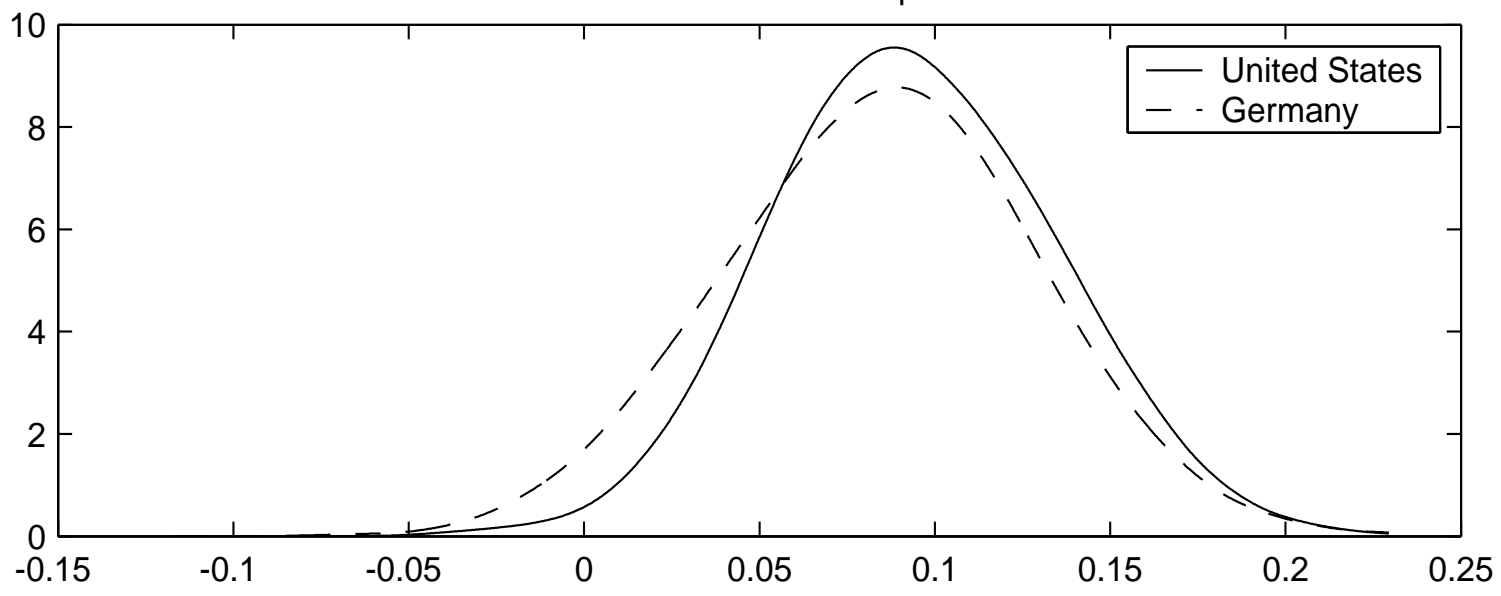

Middle Income Group

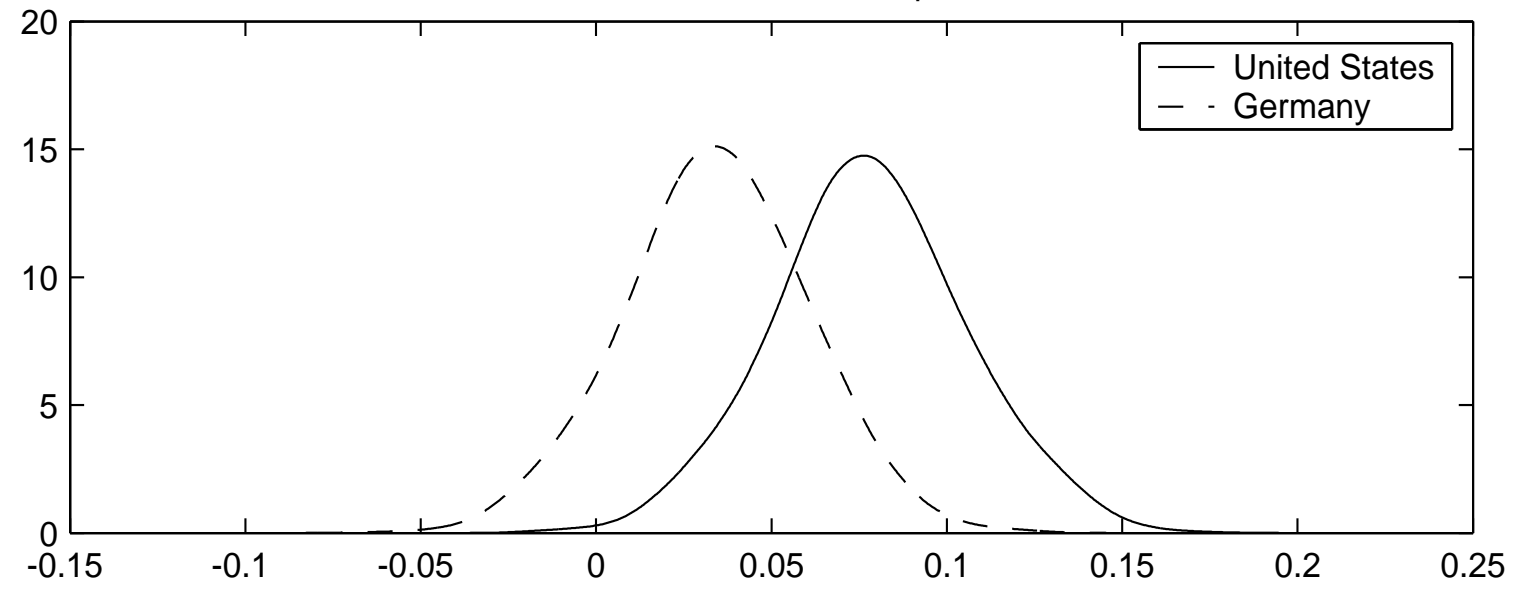

Upper Income Group

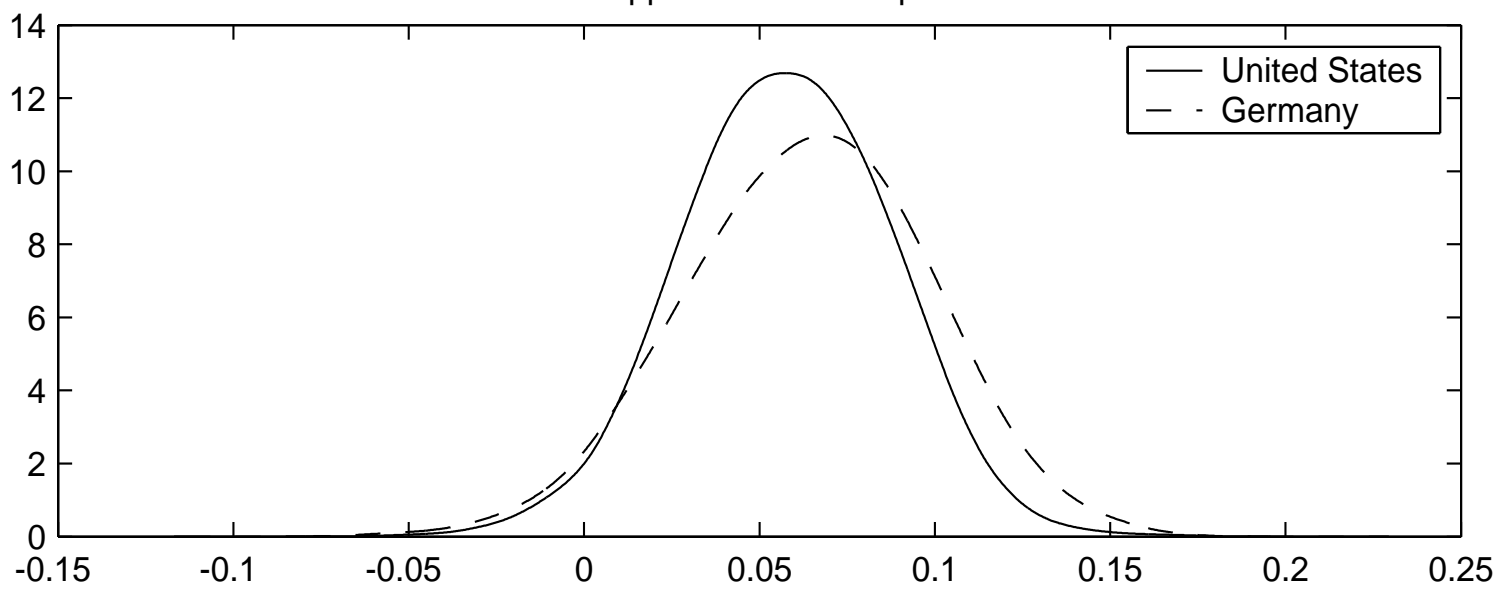

